\title{
Trend Analysis of Drought in the Guinea and Sudano-Sahelian Climatic Zones of Northern Nigeria (1907-2006)
}

\author{
Temidayo 0. Omonijo, Emmanuel C. Okogbue \\ Department of Meteorology, Federal University of Technology, Akure, Nigeria \\ Email: subzero4me@yahoo.com, emokogbue@gmail.com
}

Received 7 June 2014; revised 8 July 2014; accepted 2 August 2014

Copyright (C) 2014 by authors and Scientific Research Publishing Inc.

This work is licensed under the Creative Commons Attribution International License (CC BY). http://creativecommons.org/licenses/by/4.0/

cc) (†) Open Access

\section{Abstract}

A quantitative assessment of drought characteristics and their associated variability in the Northern Nigeria was carried out. Monthly rainfall data for all the selected locations which span a period of 100 years (1907-2006) collected from the Climate Research Unit (CRU) database were used. The resolution of the data is $0.5 \times 0.5$ degrees in longitude and latitude. The long-term rainfall records were analyzed for drought using standardized precipitation index (SPI). The 100 years of Study was subdivided into 10 decades. Using Ilwis GIS software, the SPI results were presented on a spatial digitized map of northern Nigeria. This was done using the coordinates got from the Nigerian Meteorological Agency, Lagos Nigeria. The results of SPI analysis revealed that there were several drought years in the study period. Analysis further revealed that decade 7 to decade 9 (i.e. 1967-1976, 1977-1986, 1987-1996) witnessed persistent drought in the northern Nigeria. These were classified into mild, moderate, severe and extreme drought conditions. Near normal dry or mild drought was predominant in the 100 years of study. Mild drought has the highest number of occurrence in the northern Nigeria. A closer examination shows that north eastern part of Nigeria is susceptible to moderate drought. SPI analysis for 1, 3, 6 and 12 months was carried out. According to the Nigerian Meteorological Agency Classification, 1 month represents meteorological drought, 3 months represents agricultural drought, 6 months represents hydrological drought and 12 months represents socio-economic drought. The SPI analysis revealed distinct period of negative and positive values in which negative values indicate occurrence of drought and positive values imply there is no drought. This study has provided useful information and pro-active intervention to reduce the impact of drought which will be helpful to effectively plan rain-fed agriculture in northern Nigeria.

\section{Keywords}

Drought, Northern Nigeria, Standardized Precipitation Index (SPI) 


\section{Introduction}

Drought is a period of unusually dry weather within a geographic area where rainfall is normally present, during a drought spell there is lack of precipitation. It has been noted that northern Nigeria is vulnerable to drought incidence. Frequent occurrences of drought in the zone have been largely responsible for the social backwardness and poor quality of life especially among the less privileged ones. In the southern parts of Nigeria, the current occurrence of armed robbery was believed to be related to the insurgence of migration from Sahel to the coastal areas of Lagos and Niger Delta in the early seventies [1].

Drought occurs in both high and low rainfall areas and virtually all climatic regions, although in the past, drought was only associated with arid, semi-arid and desert fringes when definition was based only on absolute rainfall amounts with drought spells now being associated with onset and cessation dates of rains and length of the rainy season, it is better defined as ineffectiveness of precipitation

Droughts occur in all climatic zones. However, its characteristics vary significantly from one region to another. Drought is a recurrent phenomenon in northern Nigeria and its vagaries affect the fortune of the predominantly farming population. If the rainfall is inadequate or if the rainy season terminates abruptly, the crops may not mature and yield will be very low [2]. Furthermore, recent studies and research in relation to the aspect of hydrology and meteorology in Nigeria since the period of Sahelian drought which began in 1969 concentrated on the socio-economic aspects of environmental degradation. Such studies focused on drought, desertification, their causative mechanisms, factors and possible methods of abatement and control [3]-[5].

The Sahelian drought that started in 1969 which lingered on till 1973 affected northern Nigeria and the calamity have had tremendous socio-economic impacts on the area where pressure on available resources is on the increase in the face of a fluctuating rainfall regime [6]. The term drought is applied to a period in which an unusual scarcity of rain causes a serious hydrological imbalance: Water-supply reservoirs empty, wells dry up, and crop damage ensues. The severity of the drought is gauged by the degree of moisture deficiency, its duration, and the size of the area affected. If the drought is brief, it is known as a dry spell, or partial drought. A drought spell is usually defined as more than 14 days without appreciable precipitation. Many nations have experienced considerable distress arising from drought occurrences, starvation and food insecurity particularly within the developing world where economies are tied to agriculture. Borno state for example is one of the most threatened land areas of Nigeria. It suffered a prolonged fifteen-year drought between 1972 and 1987 [7].

Droughts tend to be more severe in some areas than in others. Catastrophic droughts generally occur at latitudes of about $15^{\circ}-20^{\circ}$ North and South of the equator, in areas bordering the permanently arid regions of the world. Permanent aridity is a characteristic of those areas where warm, tropical air masses, descending to earth, become hotter and drier. When a poleward shift in the prevailing westerlies occurs, the high-pressure, anticyclonic conditions of the permanently arid regions impinge on areas that are normally subject to seasonally wet low-pressure weather and a drought ensues. A southward shift in the westerlies caused the most severe drought of the 20th century, the one that afflicted the African region called the Sahel for a dozen years, beginning in 1968.

Drought is a condition of extreme but short term climatic variation which results in insufficient rainfall to meet the socio-economic demands of a region in terms of water supply for domestic and industrial uses, agriculture and ecosystem. One of the earliest and most influential explanations of the cause of drought in the Sahel was that the reductions in rainfall were the result of human activity [8]. In what has come to be known as reference [8] model, decreases in vegetation cover caused by over-grazing and deforestation lead to an increase in the reflectivity or albedo of the land surface. The essence of reference [8]'s hypothesis is that this increase in reflectivity results in a reduction in the heating of the ground, which in turn reduces the heating of the atmosphere by the ground, resulting in a reduction in the convection that is essential for the formation of rainfall-generating clouds. The notion that the people of the Sahel have systematically degraded their lands through forest clearing, overgrazing, and inappropriate land-use practices has been an article of faith to many observers and researchers since the 1920s, especially by visitors to the region who have very often misinterpreted variations in annual rainfall amounts and decreases in vegetation cover, as evidence of environmental change or the encroachment of the Sahara desert. As noted by [8] and confirmed by [4], the Sahelian zone has suffered from combination of drought effects and human interference which confirm the postulation of [9]. It is a common knowledge that availability of water has been man's major concern throughout history. Also, drought in the region used to be attributed to a simple southward displacement of the Inter-Tropical Convergence Zone (ITCZ) [10]. This rather 
simplistic explanation has been rejected because it failed to explain many important characteristics of rainfall such as late onset or early cessation [11] [12].

Other studies have even suggested that the build-up in atmospheric dust, exacerbated by anthropogenic factors such as fire-wood exploitation, bush burning and poor farming practices, as well as, frequent sand storms, which cause changes in surface albedo may be responsible for large-scale climatic alterations in the Sahel [13]. The persistence of drought in parts of northern Nigeria during 1970s, 1980s and 1990s has been attributed to the prevalence of a stagnated anti-cyclonic circulation of the tropical atmosphere over areas that normally should be exposed to rising arm of tropical Hadley Cell Circulation by mid-summer [3] [14] [15]. These conditions are themselves related to the tropical component of global general circulation system.

\section{Materials and Method}

100-year (1907-2006) monthly rainfall data from the Climate Research Unit (CRU) were used for this research work. The CRU rainfall data was validated using the Surface rainfall data from the archives of the Nigerian Meteorological Agency, Oshodi Lagos Nigeria (NIMET) by using Simple Linear Regression Analysis.

One data point was selected in each state of Northern Nigeria Using Nigerian Meteorological Agency Stations' coordinate (NIMET). The 100 years (1907-2006) under study were sub-divided into 10 decades. The annual rainfall mean for each decade was analyzed in order to determine the moving decadal average of drought years.

The dataset was used to assess and monitor drought in the past 100 years.

Standardized precipitation index (SPI) was calculated from the long-term record of precipitation in each location (100 years). The data was normalized to a flexible multiple time scale such as SPI1, SPI3, SPI6, and SPI12 respectively.

\section{Study Area}

The northern region of Nigeria is located between latitude $8^{\circ} \mathrm{N}$ and $14^{\circ} \mathrm{N}$ and longitude $4^{\circ} \mathrm{E}$ and $14^{\circ} \mathrm{E}$. The regions are as follow (Figure 1); Kebbi, Sokoto, Zamfara, Katsina, Kano, Jigawa, Yobe, Borno, Niger, Kaduna, Bauchi, Kwara, Kogi, Abuja, Nasarawa, Benue, Plateau, Taraba and Adamawa. All the regions have two distinctive seasons: wet and dry seasons. Rainfall in this region is highly variable and onset of the rain is erratic. The rainfall intensity is very high between months of July and August. The southern region of Nigeria receives more rain and is less vulnerable compared to the northern region.

\section{Data Analyses}

\subsection{Standardized Precipitation Index (SPI)}

The understanding that a deficit of precipitation has different impact on groundwater, reservoir storage, soil moisture, snowpack and stream flow led to development of SPI [16]. SPI is a simple index which is calculated from the long-term record of precipitation in each location (100 years). The data will be fitted to normal distribution and be normalized to a flexible multiple time scale such as SPI1, SPI3, SPI6, and SPI12 respectively.

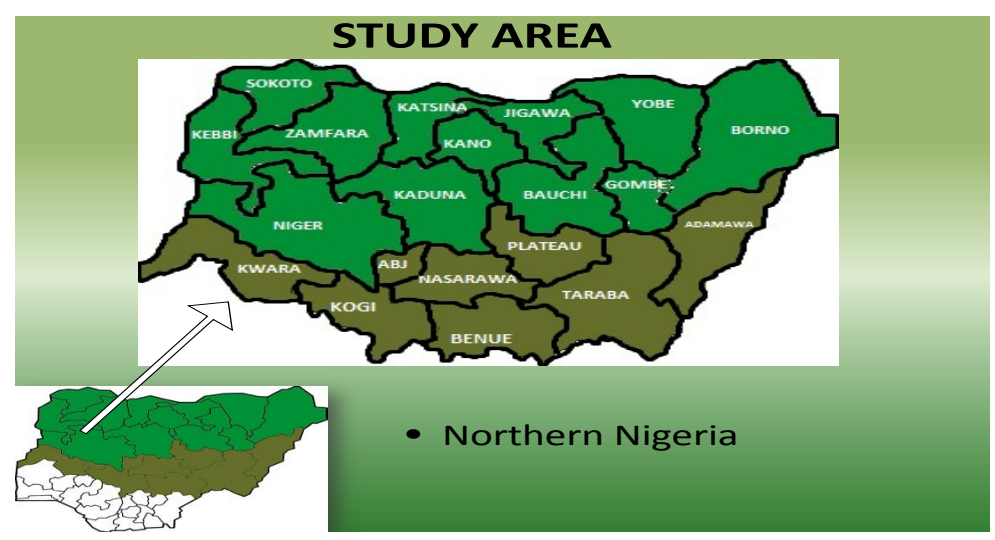

Figure 1. Map of Nigeria showing the study area. 


\subsection{SPI Time Scale Interpretations}

1-month SPI (August) reflects relatively short time soil moisture during growing seasons; it is more accurate because the distribution has been normalized.1 month SPI addresses meteorological drought.

3-month SPI (June-August) provides a comparison of the precipitation over a specific 3-month period with the precipitation totals from the same 3-month period for all the years included in the historical record. This time scale addresses both Meteorological and Agricultural droughts.

6-month SPI (April-September) can be very effective in showing the precipitation over distinct seasons. 6-month SPI may also begin to be associated with anomalous stream flows and reservoir levels; this timescale is good for monitoring hydrological drought.

12-month SPI (January-December) reflects long-term precipitation patterns. These timescales are usually tied to stream flows, reservoir levels, and even groundwater levels at longer timescales.

Reference [16] used the classification system shown in the SPI values in Table 1 to define drought intensities resulting from the SPI. Reference [16] also defined the criteria for a "drought event" for any time scales. A drought event occurs any time the SPI is continuously negative and reaches where SPI is -1.0 or less. The event ends when SPI becomes positive.

The Standard Precipitation Index is then calculated for selected time step using:

Standardized Precipitation Index (SPI)

$$
\begin{gathered}
\mathrm{SPI}=\frac{\left(R_{i j}-\bar{r}_{i}\right)}{\delta_{i}} \\
\sigma_{i}=\sqrt{\frac{\sum_{1}^{n}\left(R_{i j}-\bar{r}_{i}\right)^{2}}{N}}
\end{gathered}
$$

where;

SPI $=$ Standard Precipitation Index for station $i$ and year $j$,

$R_{i j}=$ annual rainfall for station $i$ and year $j$,

$\bar{r}_{i}=$ mean annual rainfall at station $i$,

$\sigma_{i}=$ standard deviation of the annual rainfall for station $i$,

$N=$ number of specific years for sample station.

\section{Results and Discussion}

\subsection{Validation of Data Used}

CRU data is a global data, therefore it was necessary for the data to be validated. This was done by using the 30 year surface monthly rainfall data (1971-2000). The surface data was obtained from the archives of the Nigerian Meteorological Agency, Lagos Nigeria (NIMET). The monthly mean CRU data was validated with the Monthly mean surface data by using simple linear regression analysis [17]. Validation was done for 3 selected stations (i.e. a station per ecological zone) within the study area.

Table 1. Showing SPI vales and respective interpretations.

\begin{tabular}{cc}
\hline SPI VALUES & INTERPRETATION \\
-2.0 and less & Extremely dry \\
-1.5 to -1.99 & Severely dry \\
-1.0 to -1.49 & Moderately dry \\
-0.99 to +0.99 & Near normal \\
1.0 to 1.49 & Moderately wet \\
1.5 to 1.99 & Very wet \\
2.0 and above & Extremely wet \\
\hline
\end{tabular}


The expressions Figures 2(a)-(c) show there is a good relationship between CRU data and NIMET's surface data.

\subsection{Spatial Variation of 1-Month SPI (SPI1)}

Rainfall over Northern Nigeria peaks in August; this month's rainfall was used to analyze SPI1 for the ten decades. The spatial trend of SPI1 drought classification is shown in Figure 3(a). Generally, drought incidences were most intense in the 8th decade while decade 3 and 4 are the wettest. It was observed that August Rainfall is more in upper-North between decades 2 and 6 . The reverse was the case since decade 7.

In the first decade, Mild drought was dominant over most parts of Northern Nigeria except for parts of Taraba, Plateau and Kaduna where mildly wet was observed. In the second decade, mildly wet dominated (indicating a wetter August unlike the first decade), this condition was observed across the region except for Borno, Taraba Plateau and part of Adamawa while mild drought was observed in the remaining parts of the region. Mildly wet was also dominant in the third decade except for eastern part of Borno where mild drought was observed. Similarly, in decade 4 mildly wet virtually dominated except for some parts of Sokoto and Niger States. In the fifth decade there was relative reduction in August rainfall resulting in Mild drought in Niger, Taraba, Plateau, Abuja, parts of Kaduna, and Borno while states in the upper-North such as Sokoto, Zamfara, Kano, Jigawa experienced mild drought. In decade 7, mild drought covers all states in the North-West while mildly wet was observed in parts of Niger, Abuja, Plateau and all North-East States. The most severe drought incidence of period of study was observed in decade 8, simply because it includes period of the renown 1983 drought; moderate drought was observed in parts of Borno, Niger and Abuja witnessed mildly wet condition. In the ninth decade, mild wet was observed over Taraba, Abuja and parts of Kaduna, Plateau and Niger while mildly drought was observed in other parts. In the decade 10, mildly wet was observed in parts of Borno, Zamfara Katsina, Kaduna and Niger while other states experienced mild drought.

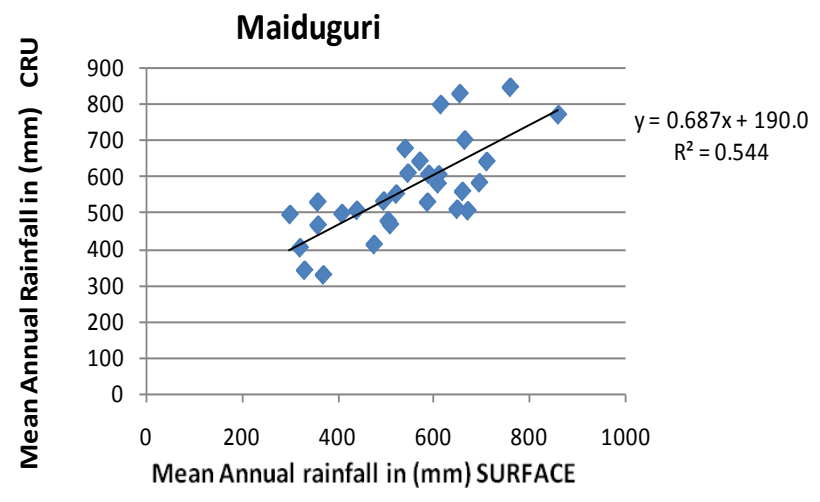

(a)

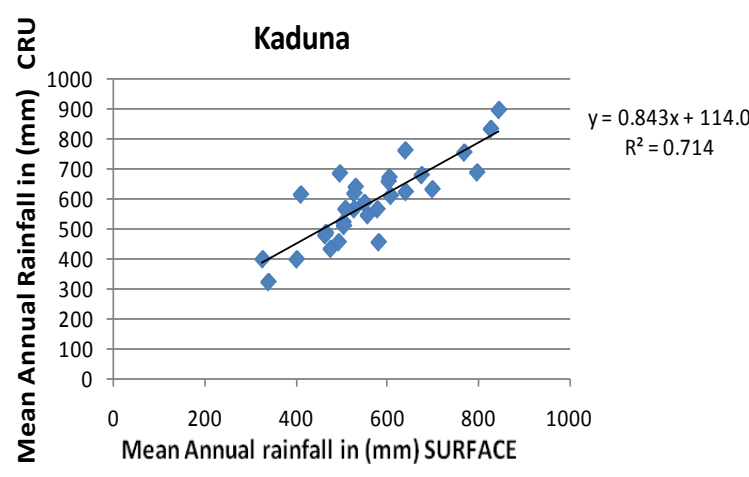

(b)

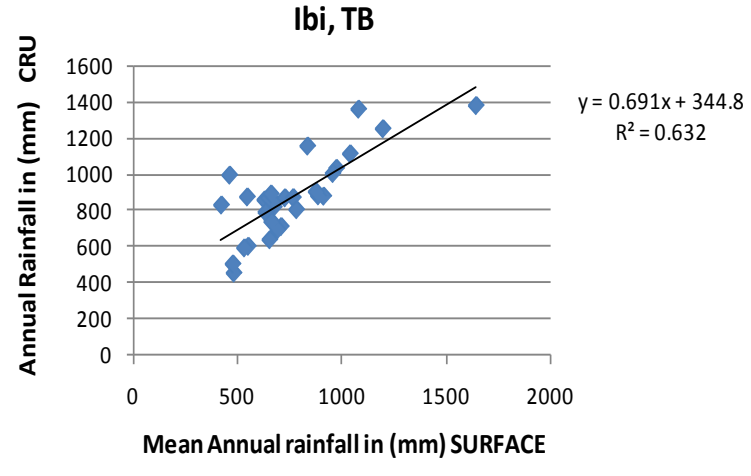

(c)

Figure 2. (a)-(c) Simple linear regression analysis showing relationship between CRU rainfall data and NIMET's rainfall data for Maiduguri, Kaduna and Ibi. 


\subsection{Spatial Variation of 3-Month SPI (SPI3)}

This SPI time scale was computed using the monthly rainfall of June, July and August. This period is the onset of rainy season over most parts of Northern Nigeria. The spatial trend of SPI3 drought classification is shown in Figure 3(b). In decade 1, Mild drought was observed in Borno, Yobe, Jigawa, while other parts are of mildly
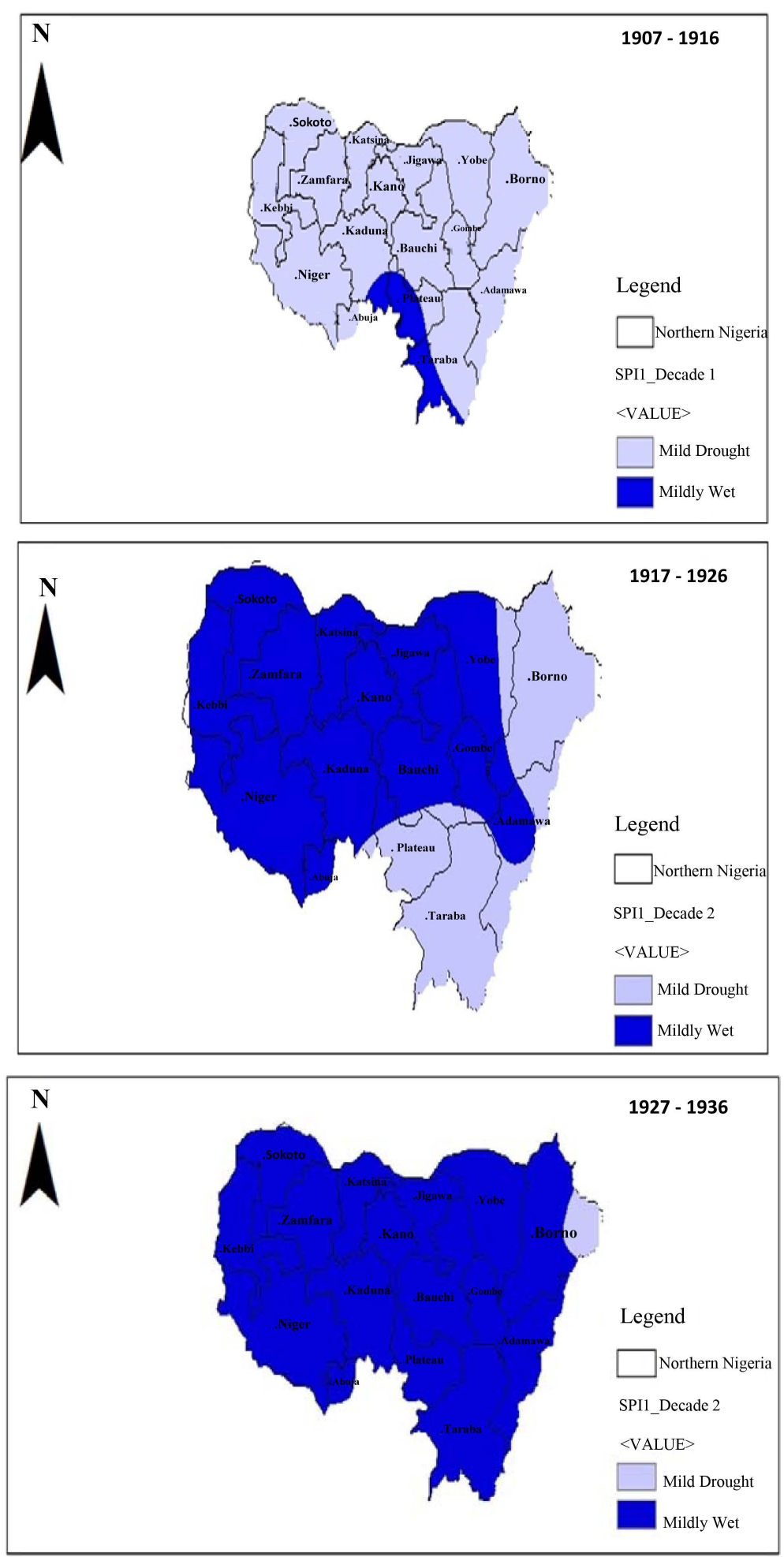

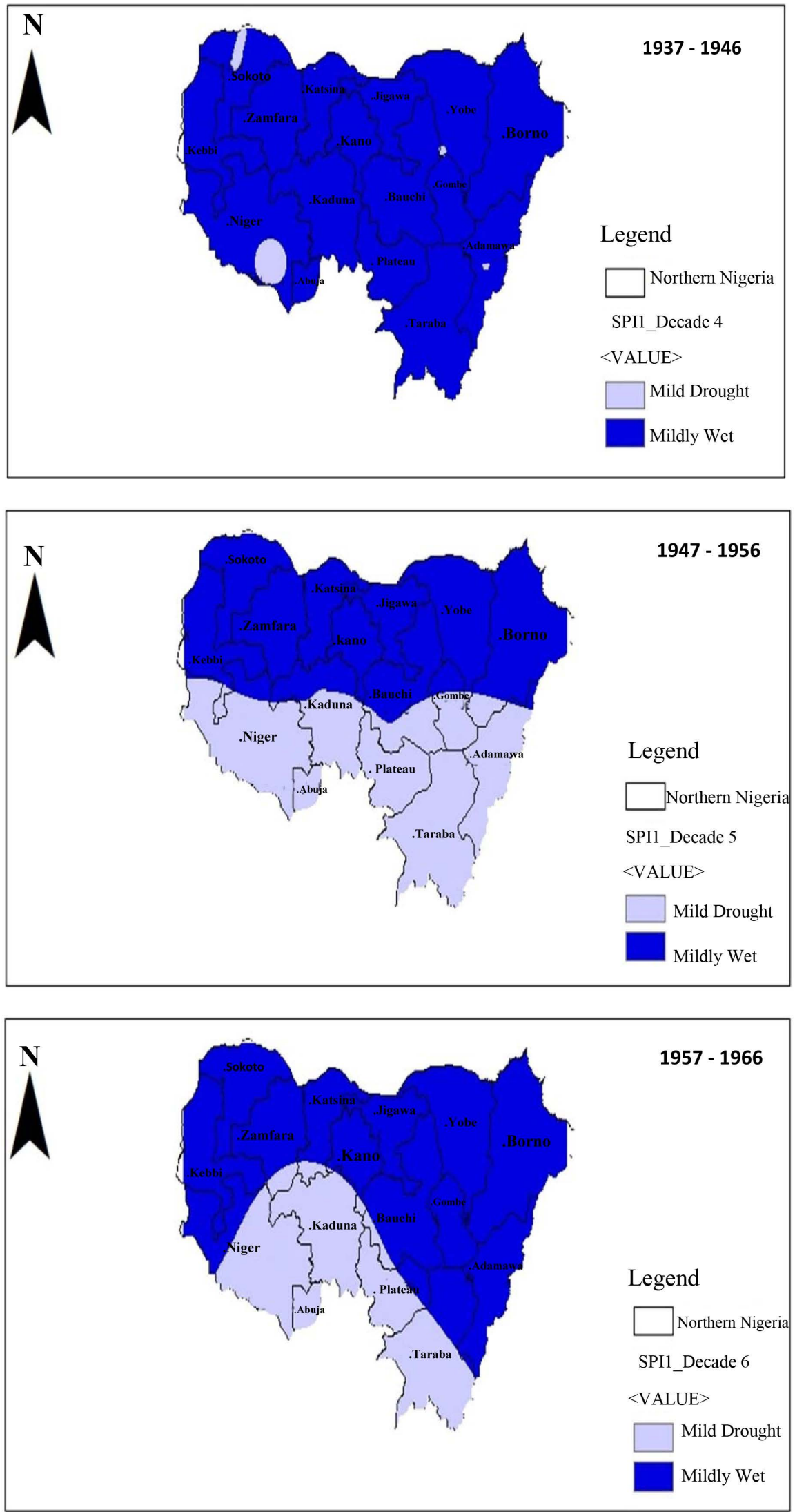

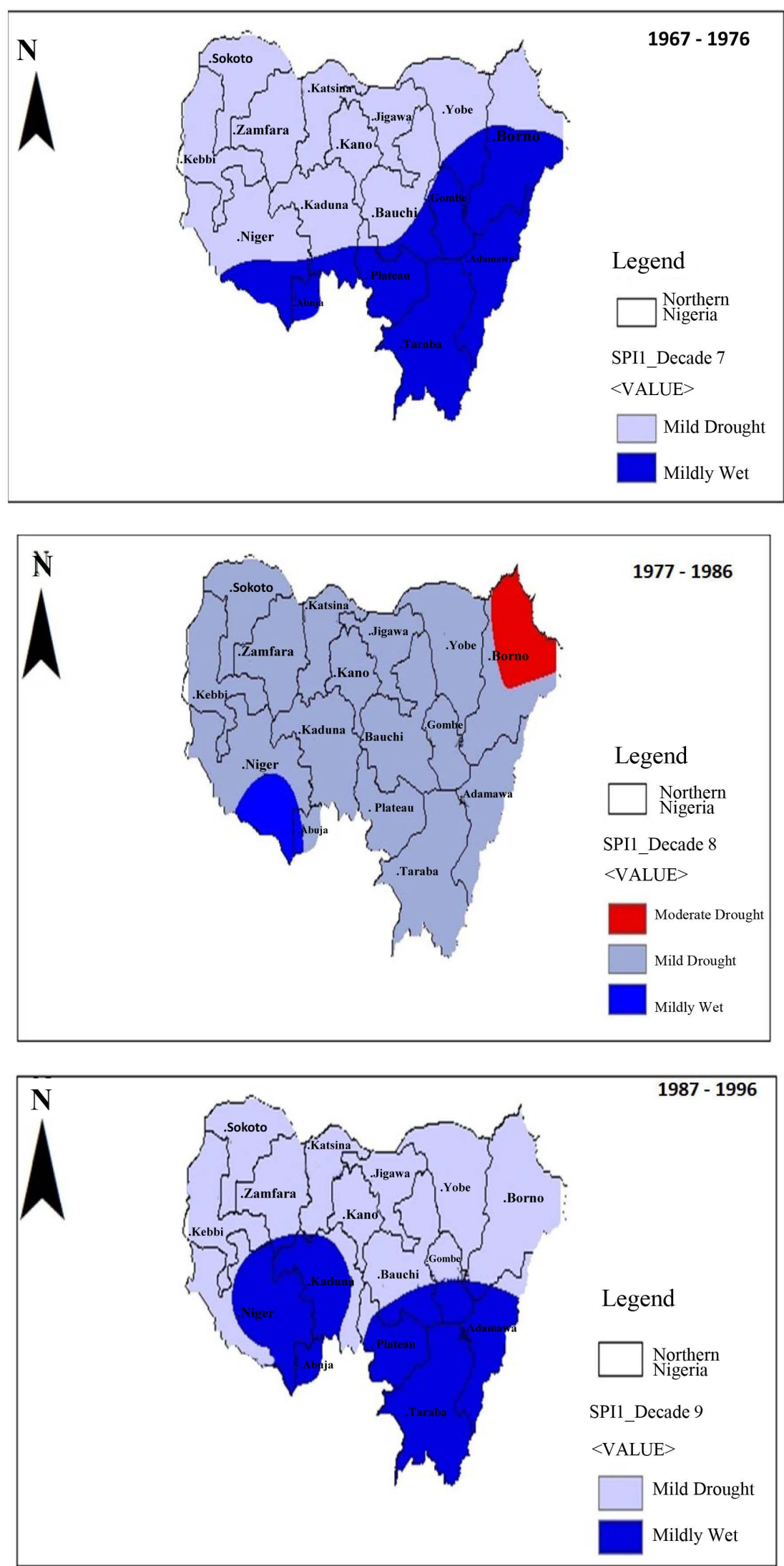


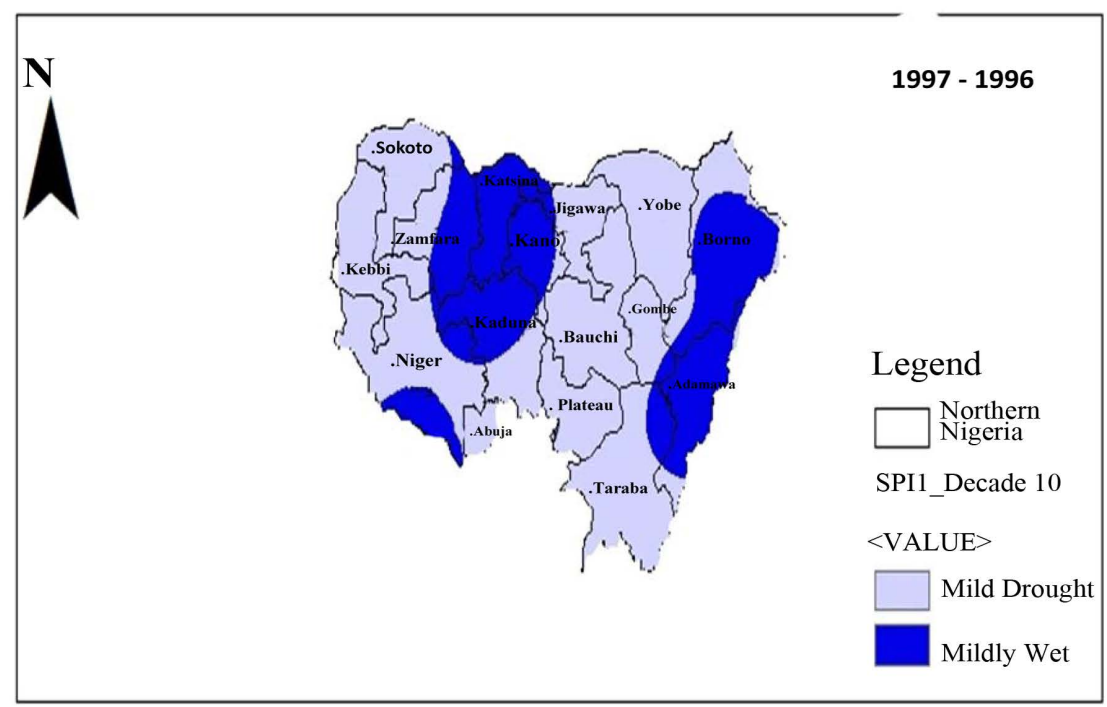

(a)
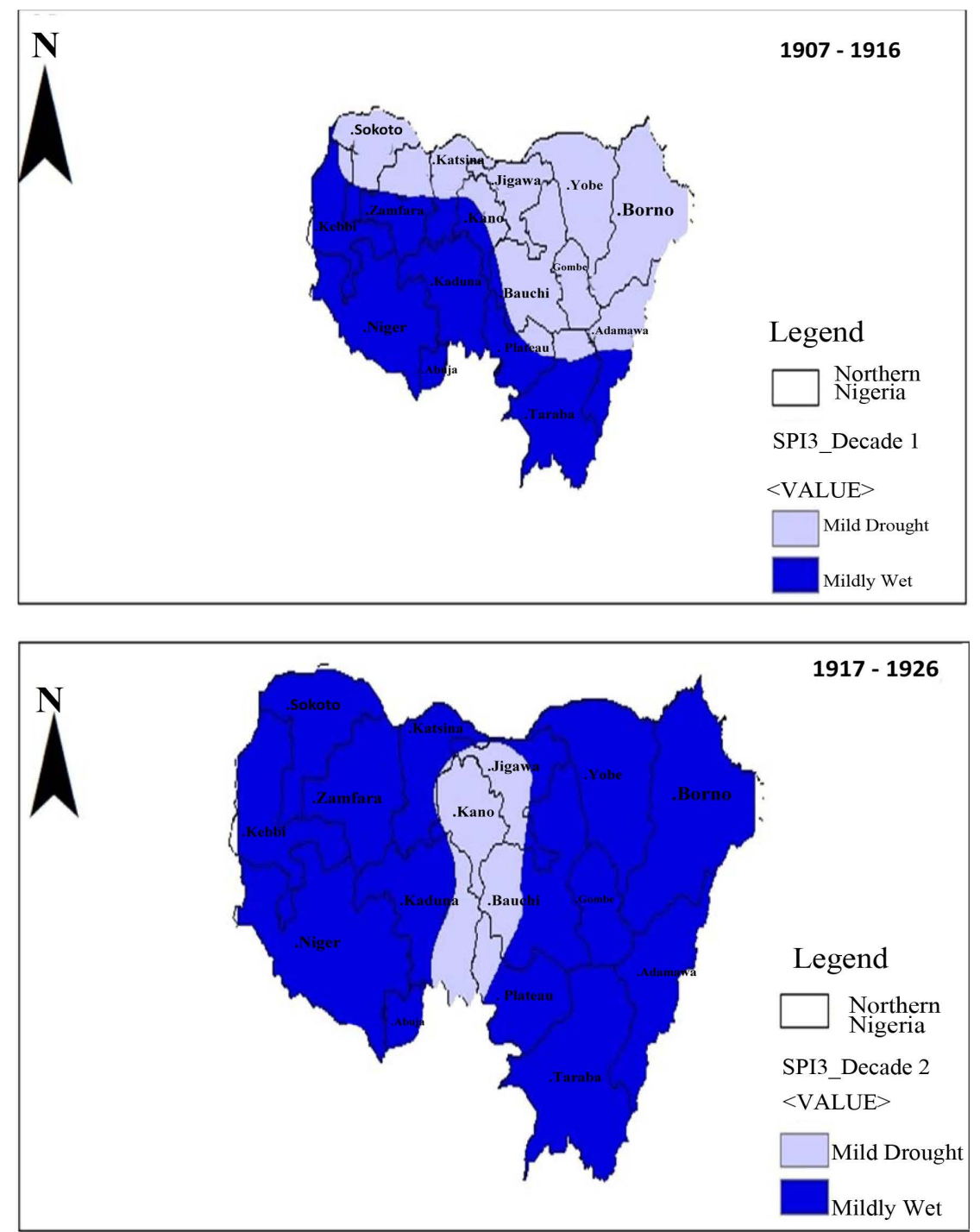

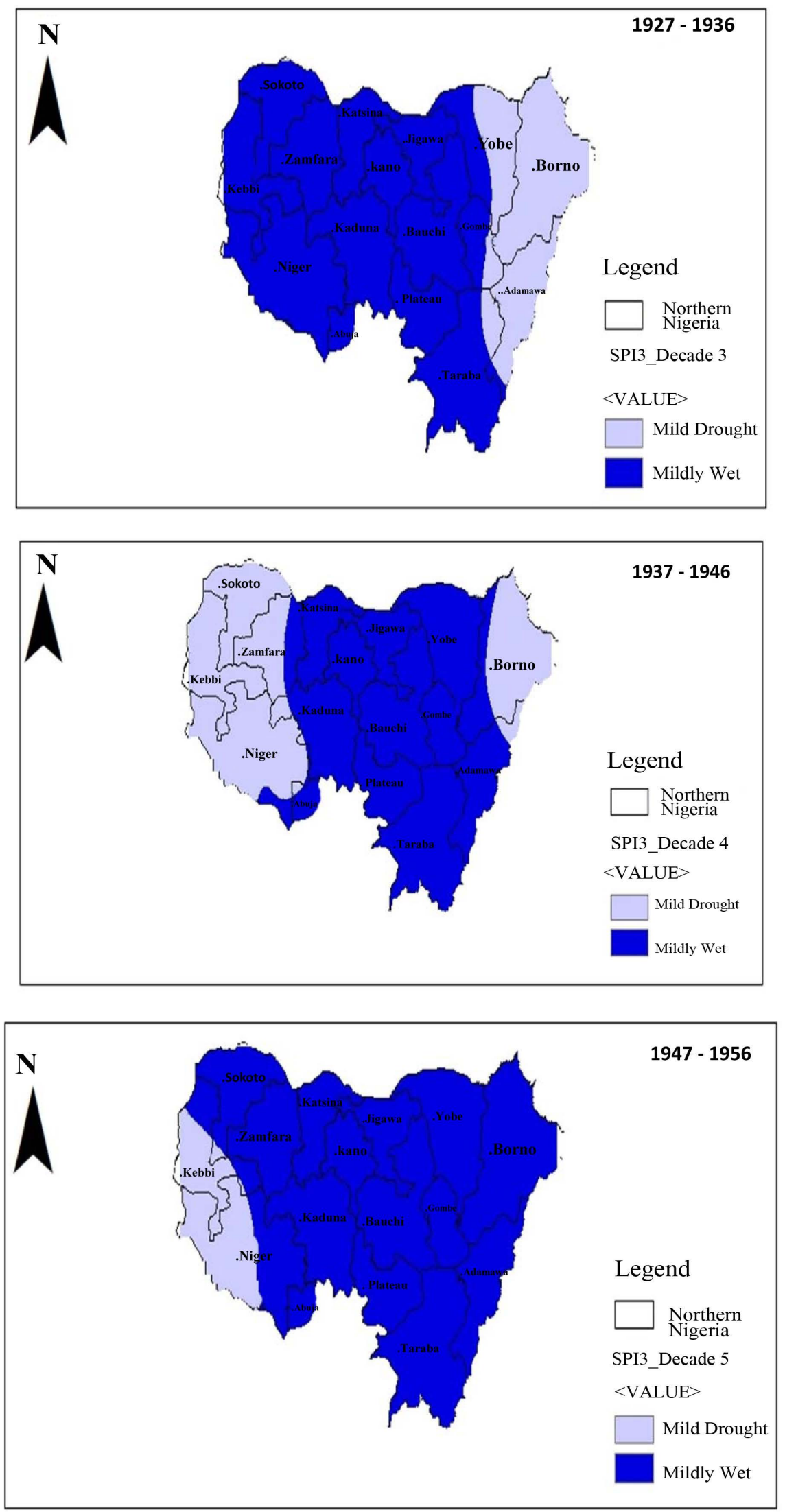

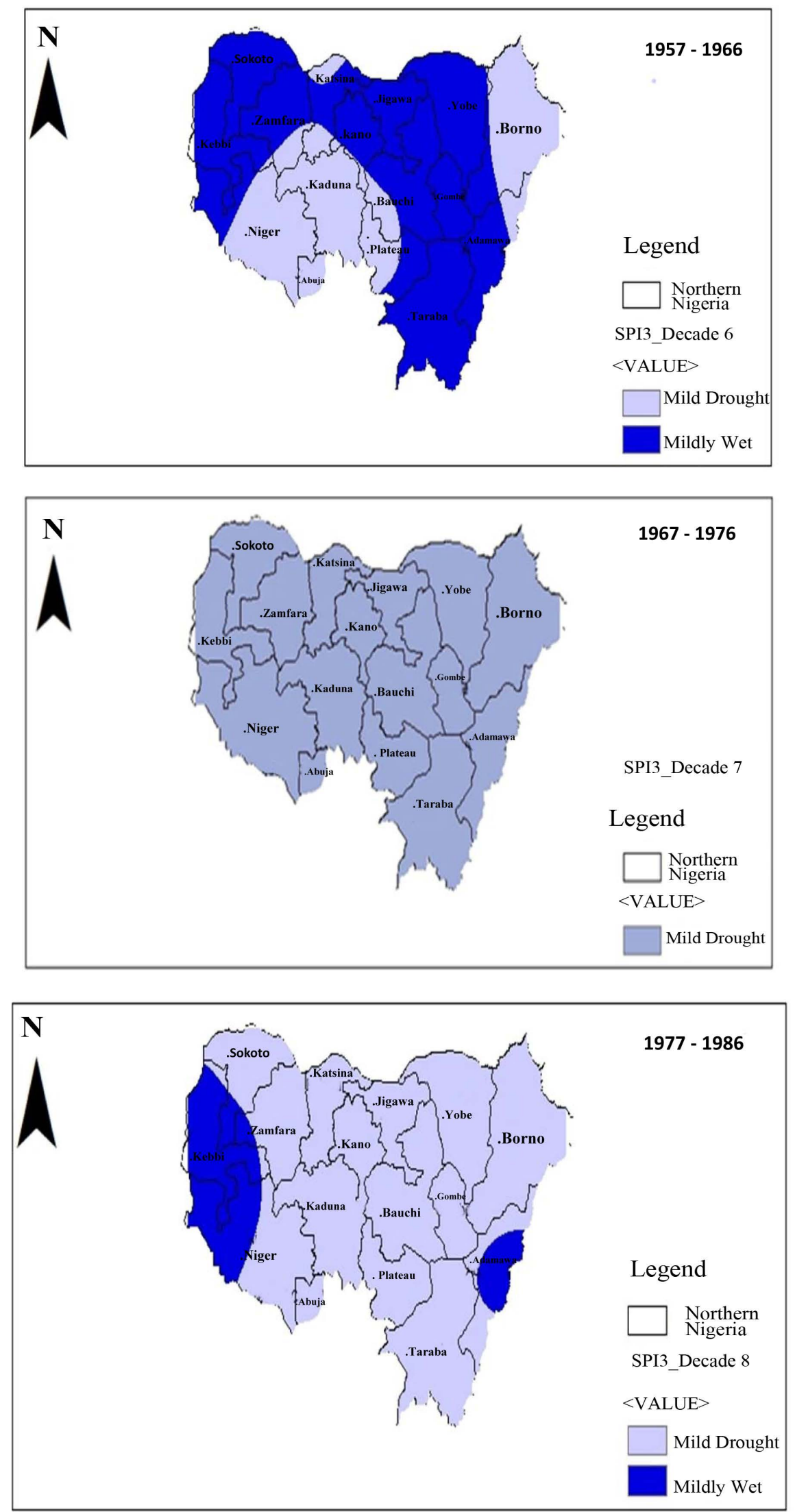

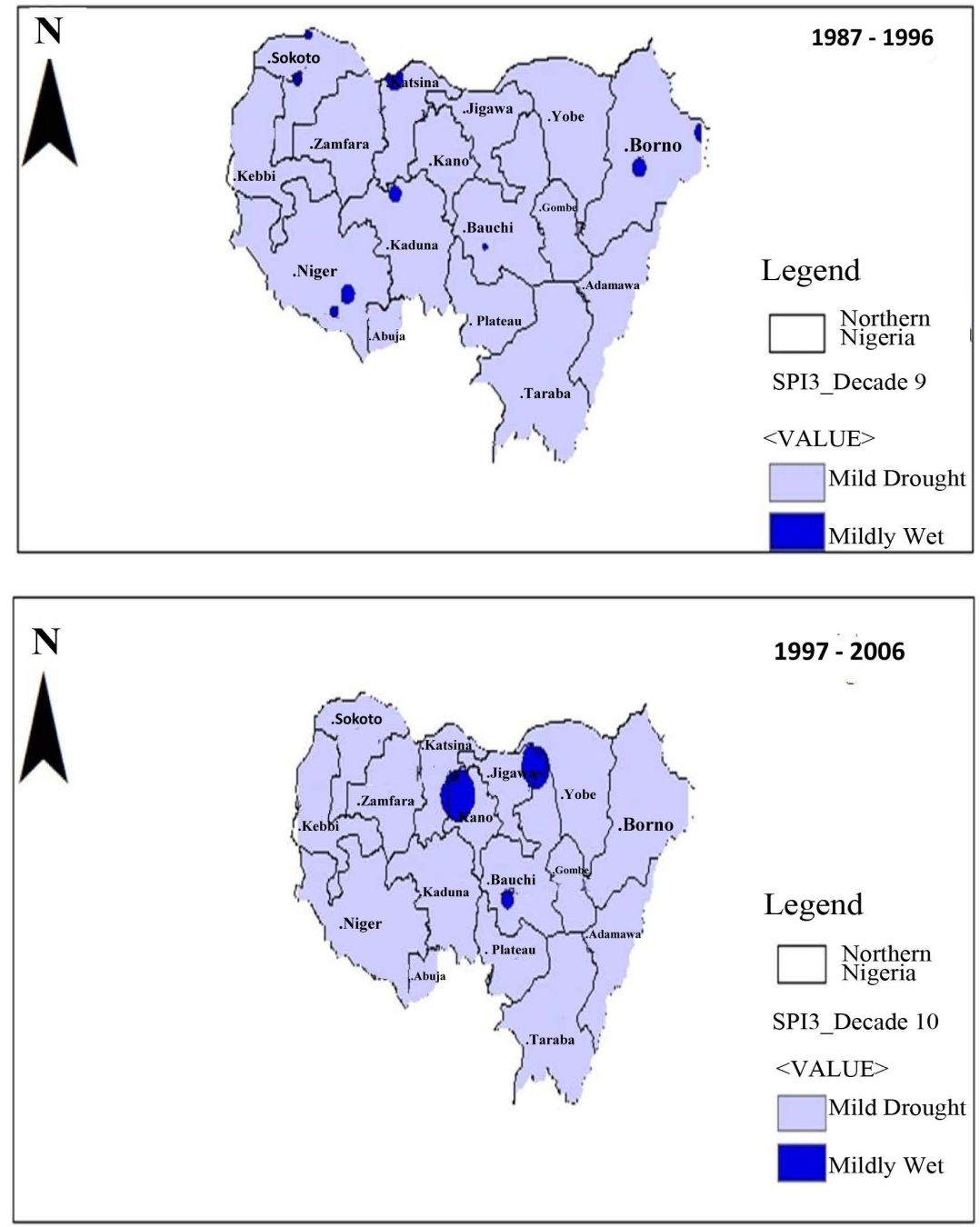

(b)

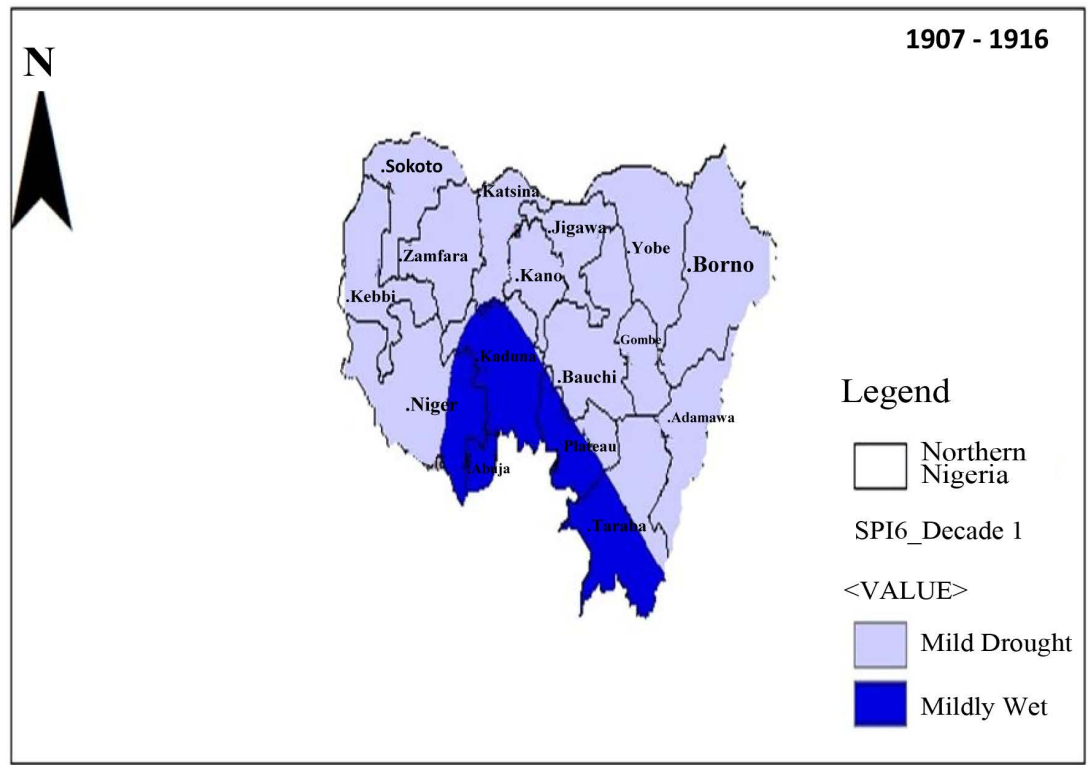



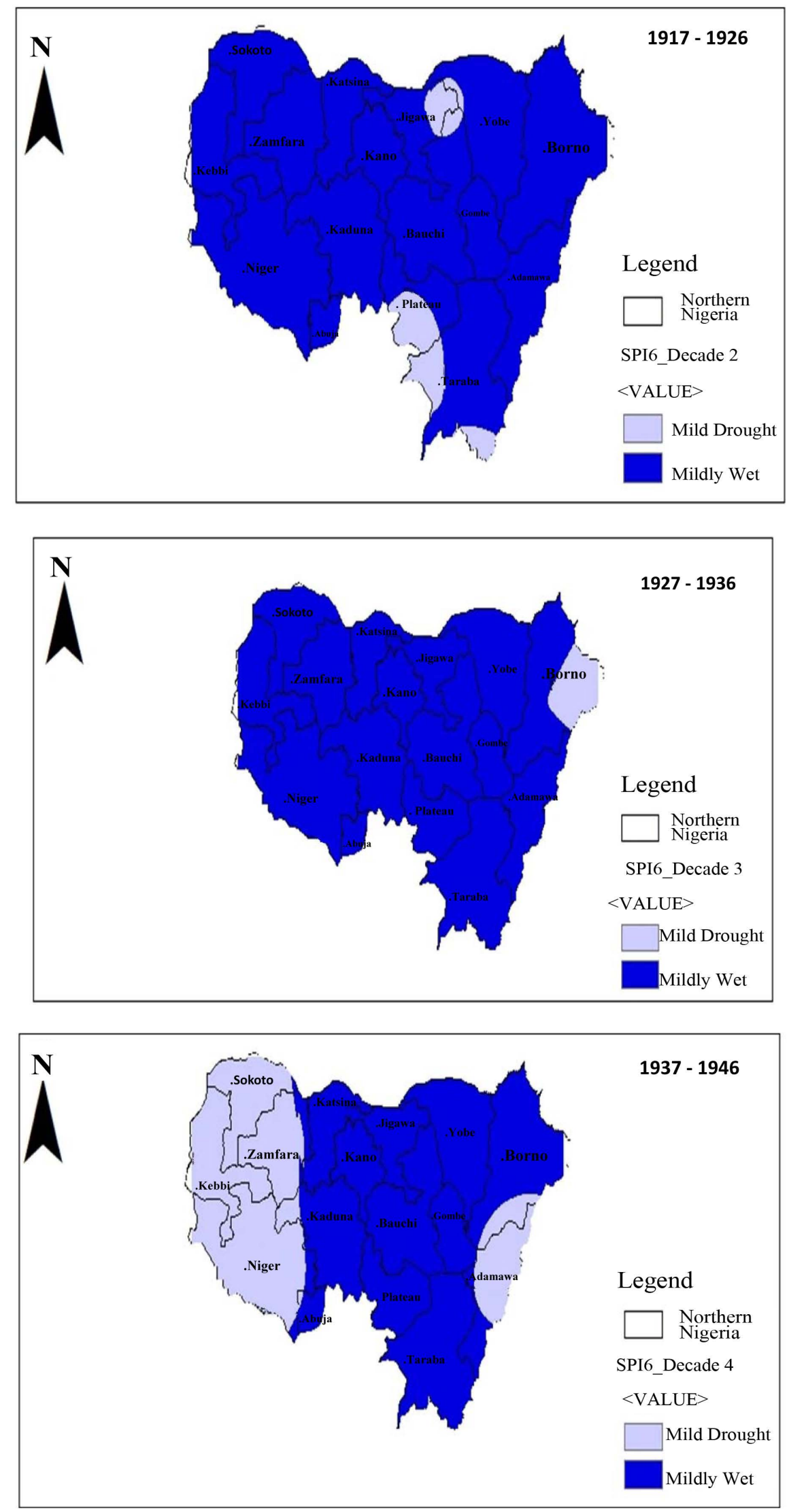

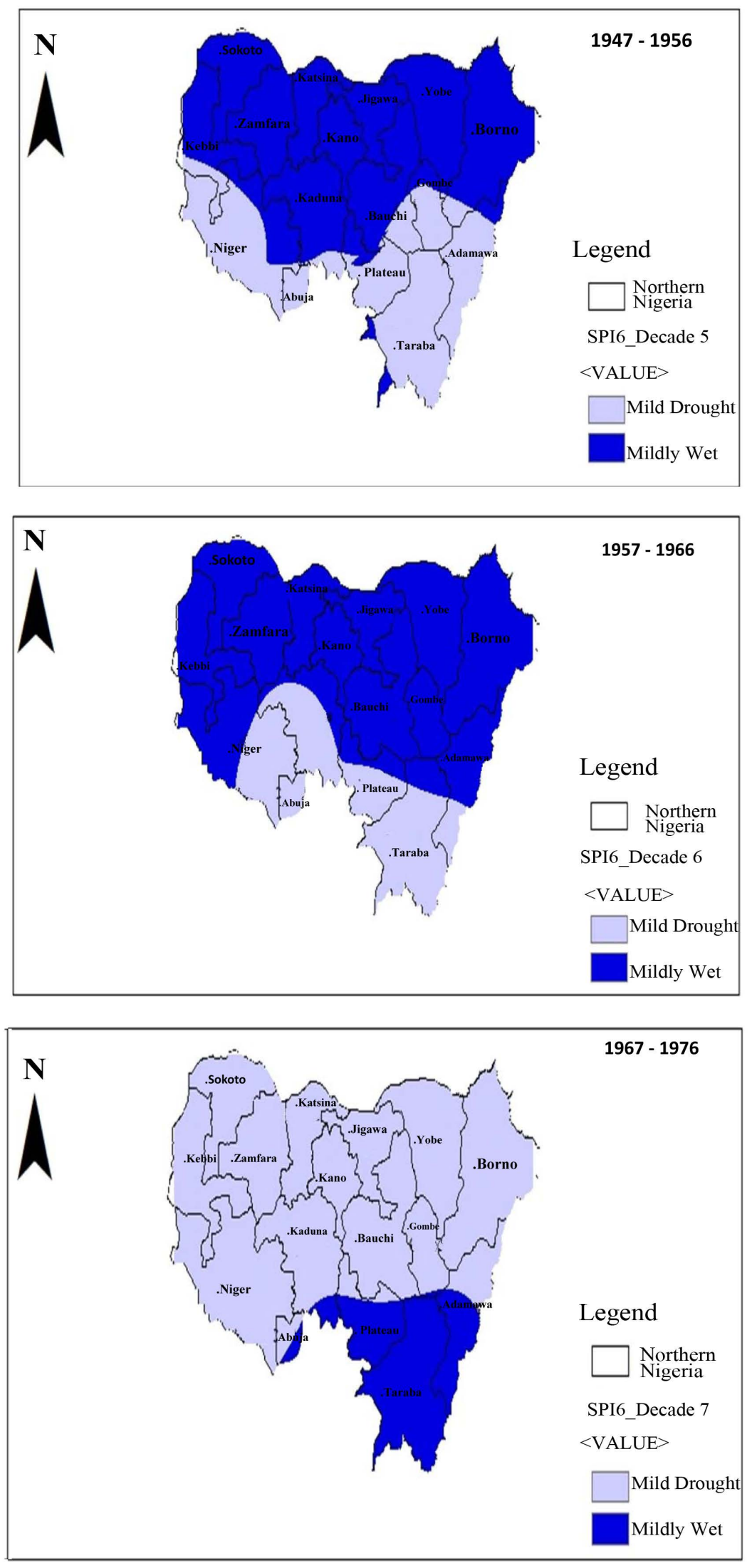

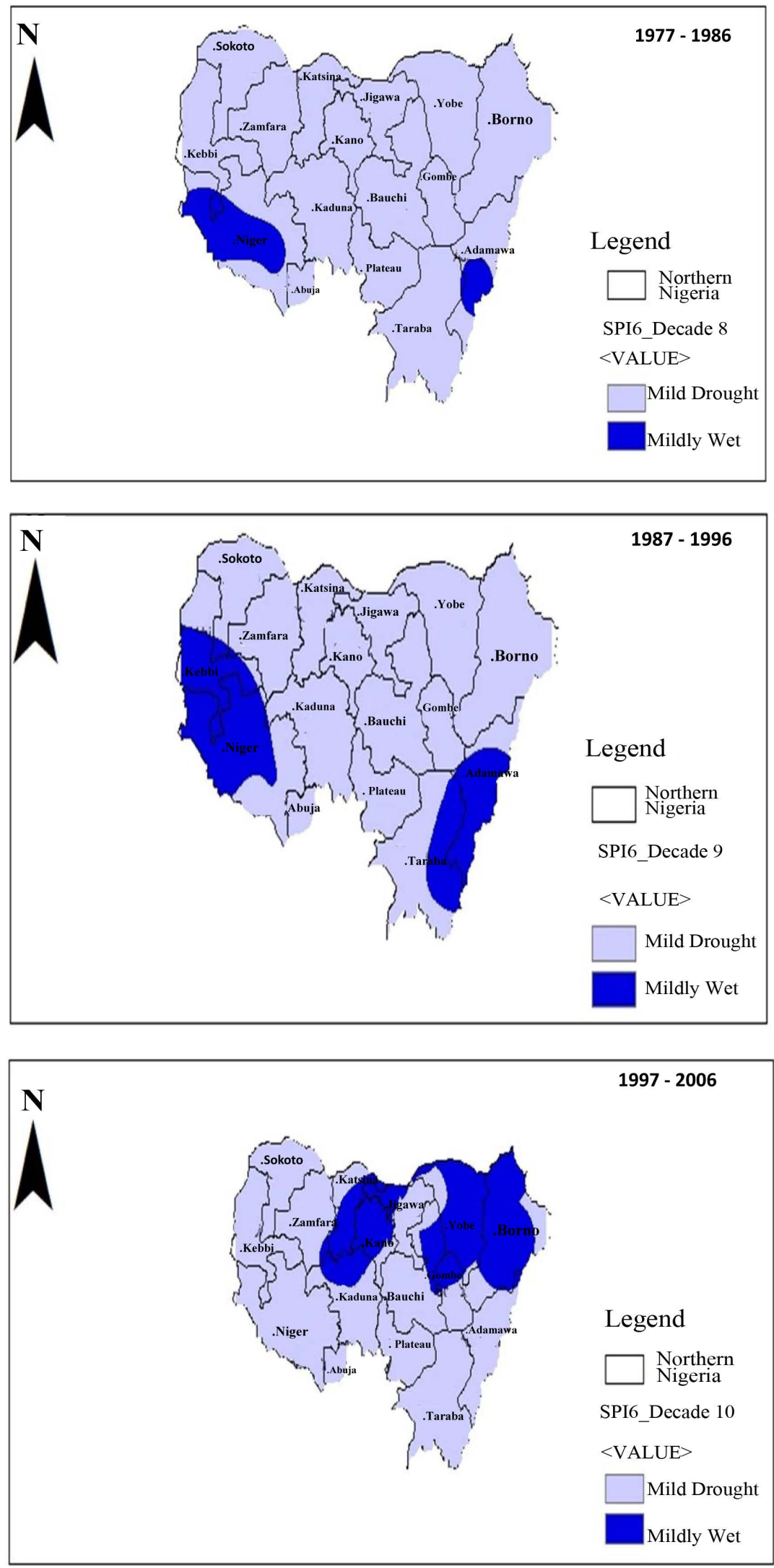

(c) 

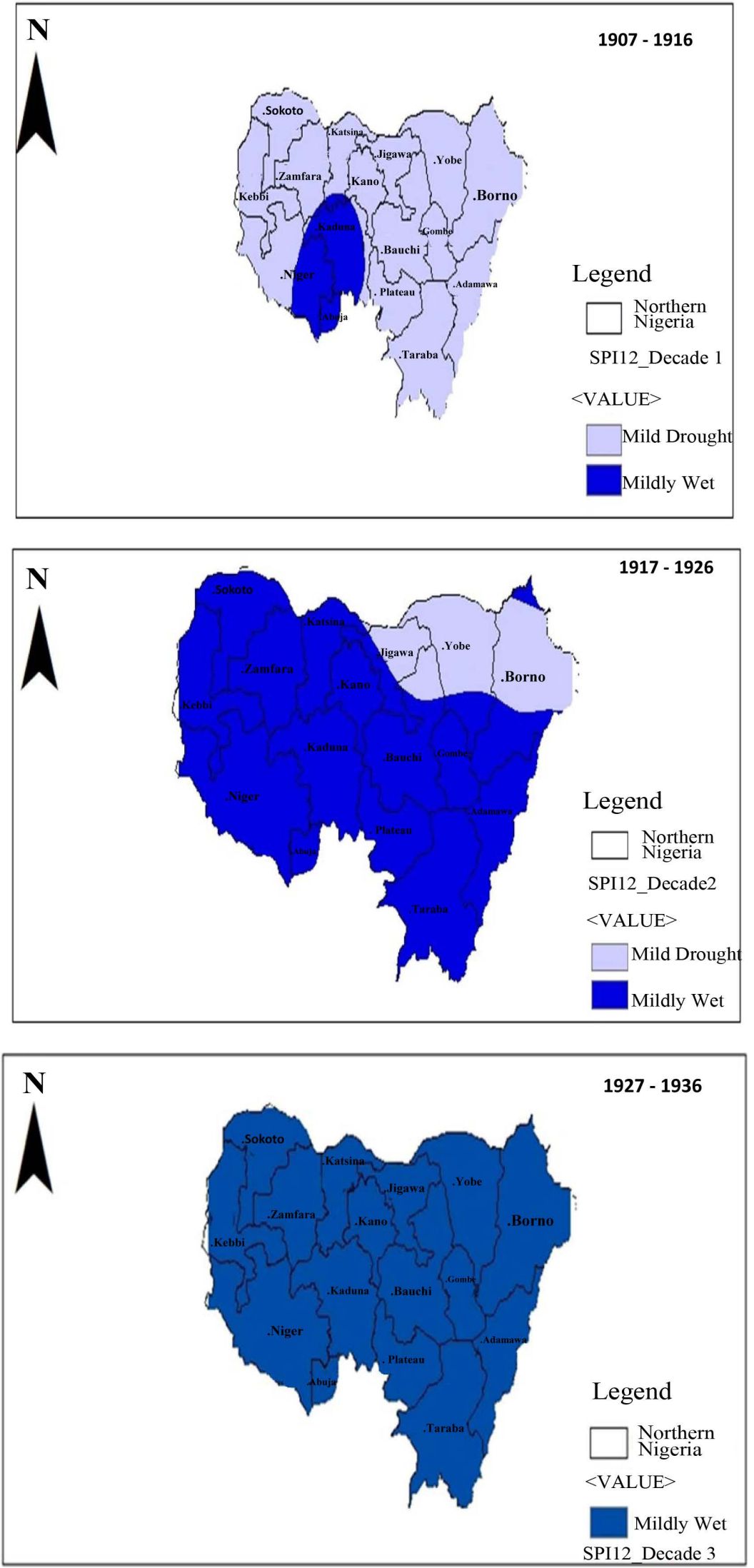

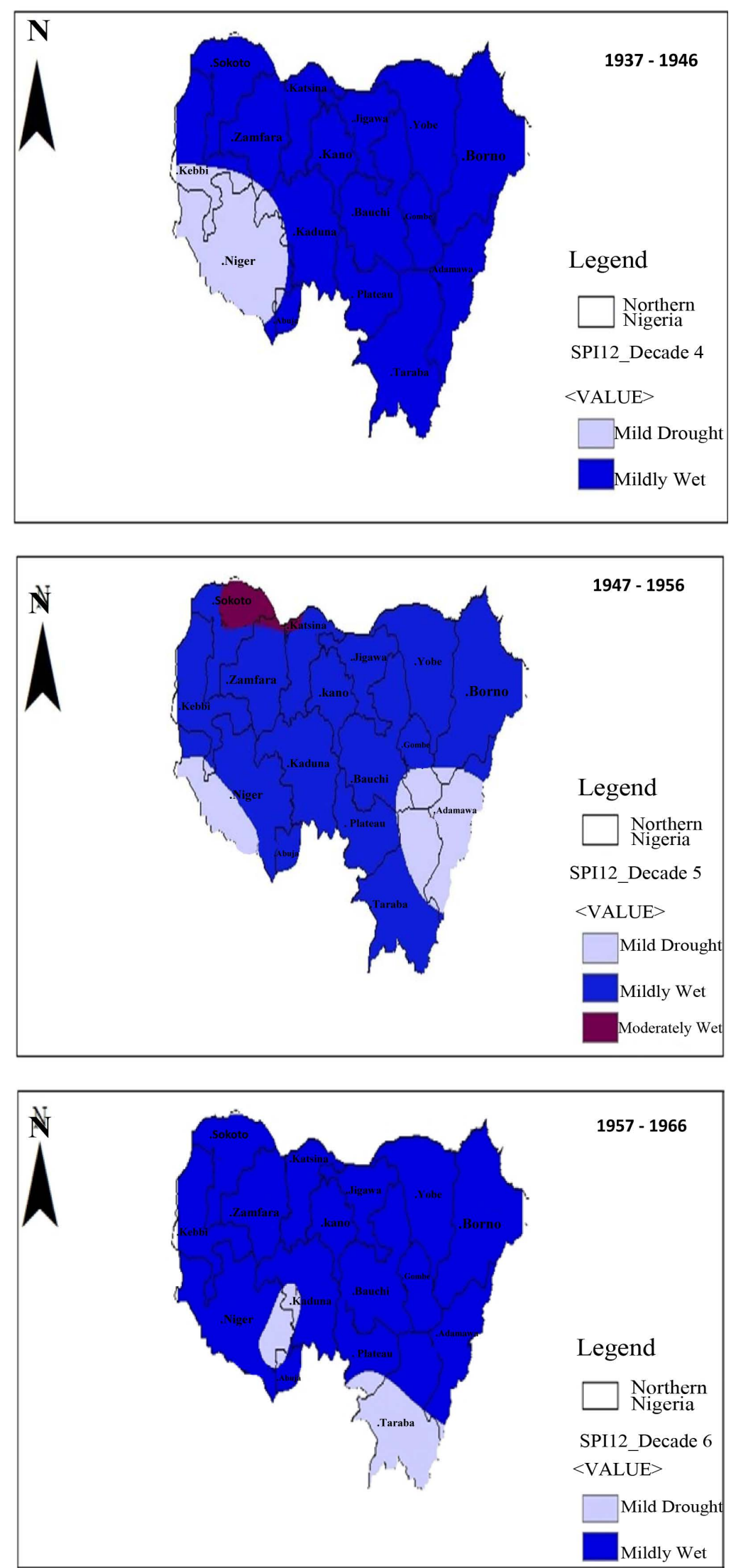

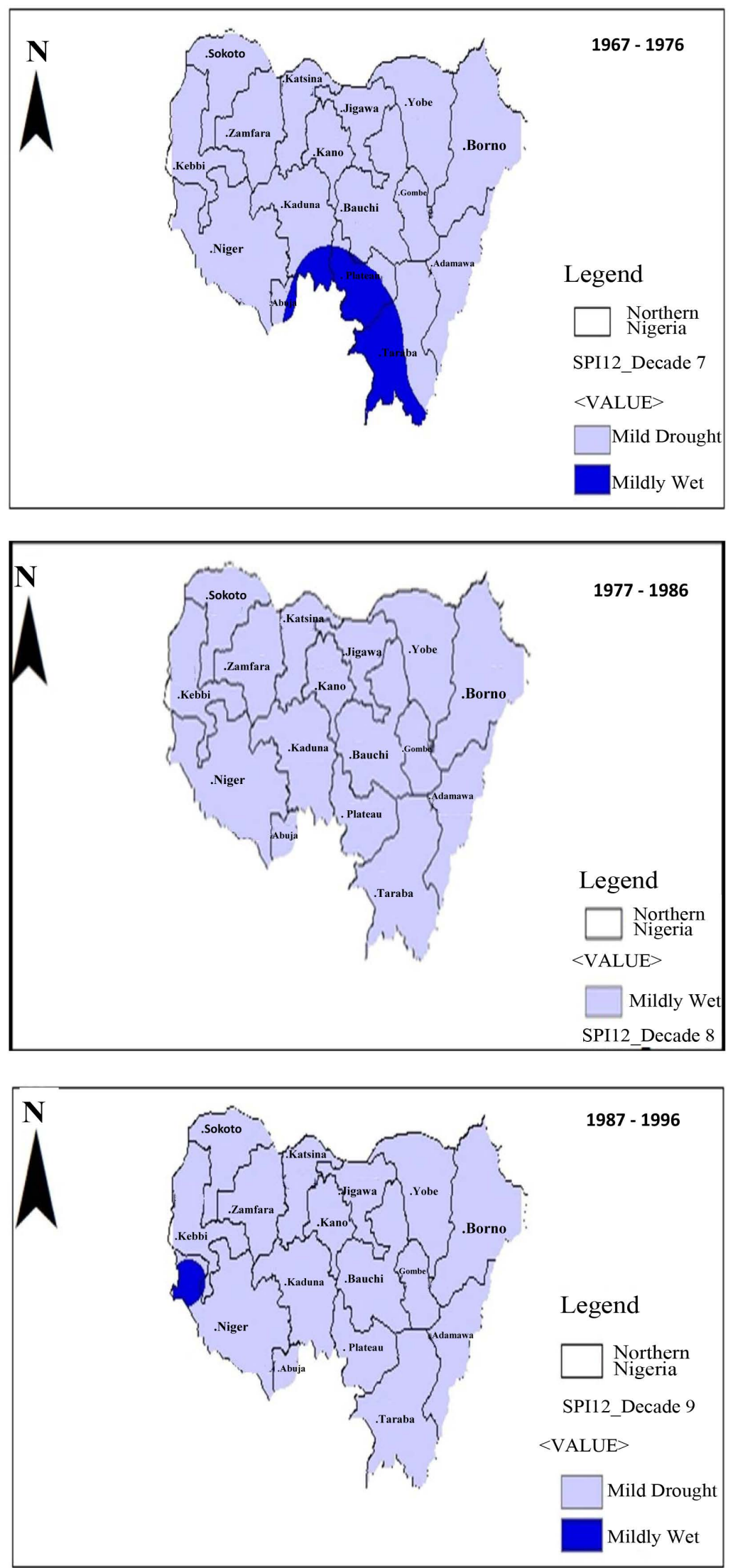


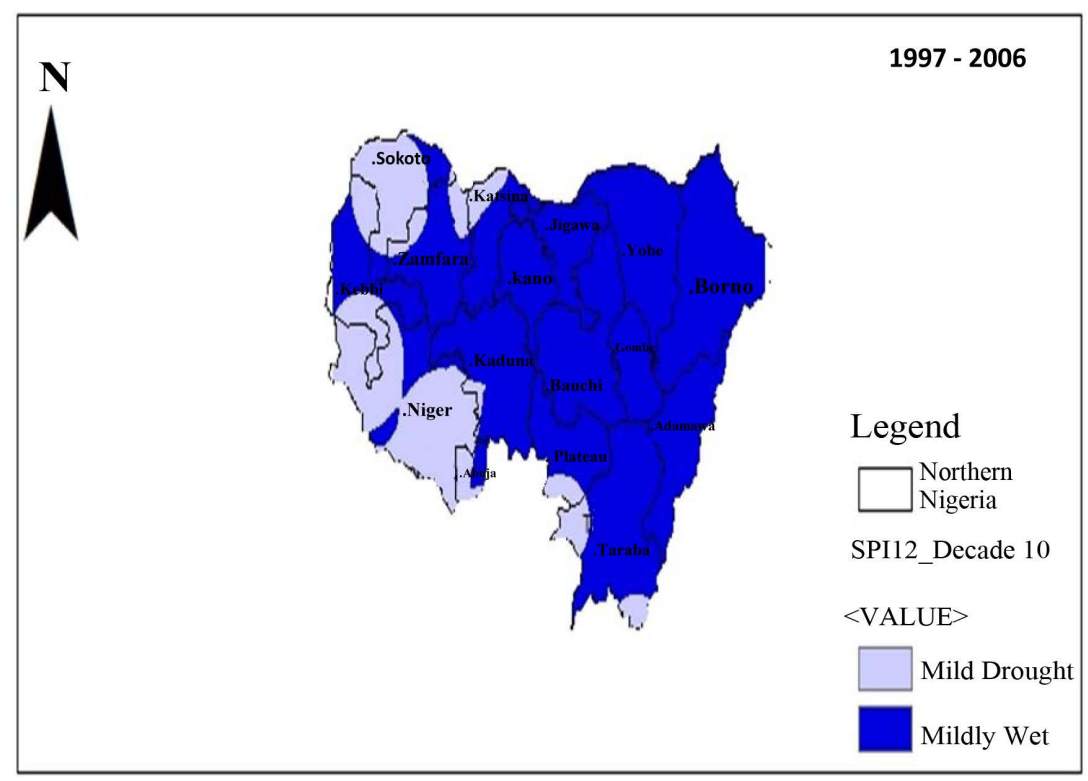

(d)

Figure 3. (a) Map of northern nigeria for SPI1 (Decade 1-Decade 10); (b) Map of northern nigeria for SPI3 (Decade 1-Decade 10); (c) Map of northern nigeria for SPI6 (Decade 1-Decade 10); (d) Map of northern nigeria for SPI12 (Decade 1-Decade 10).

wet condition. There was reduced rainfall receipt in Kano and Parts of Jigawa, Kaduna and Bauchi leading to mild drought over these states in decade 2 while other mildly wet was observed in other parts of the study area. Borno, Adamawa, parts of Yobe and Taraba experienced mild drought in decade 3 while mildly wet was observed in other parts of the study Area. In decade 4, mild drought was observed over Sokoto, Kebbi, Niger, parts of Zamfara and Borno States while Mild drought was observed in other parts of the study area. In the fifth decade, mild drought covers less area (parts of Kebbi and Niger) while mildly wet was observed in other portion of Northern Nigeria.

In decade 6, mild drought was observed in Niger, Kaduna, Borno and parts of plateau while other parts are of mildly wet. Perpetual dryness was observed between decade 7 and decade 10 over parts of Northern Nigeria, early rainfall reduced leading to mild drought in most parts of the study area in the last four decade except in Kebbi, parts of Niger and Adamawa in decade 8.

\subsection{Spatial Variation of 6-Month SPI (SPI6)}

This was computed using the first 6months of rainy season (April-September). The spatial trend of SPI6 drought classification is shown in Figure 3(c). In decade1, mildly wet was observed in parts of Kaduna, Taraba, Plateau, Niger and Abuja while other parts of Northern Nigeria experienced mild drought. Decade 2 was wetter. Mildly wet condition was observed except for parts of Plateau, Taraba and Jigawa. Similarly, mildly wet was observed almost across Northern Nigeria in decade 3 except for parts of Borno where mild drought was observed. In decade 4, mild drought was observed in Sokoto, Kebbi, Niger, Zamfara and Adamawa States while other parts of the study area experienced mildly wet condition. Mild drought condition was observed in southern part of the study area which covers Niger, Abuja, Plateau, Taraba and Adamawa in the fifth decade while mildly wet was observed in other parts. There was increase in the spatial coverage of mild drought since decade 7 which was sustained till decade 10 .

\subsection{Spatial Variation of 12-Month SPI (SPI12)}

SPI12 was computed using the mean monthly rainfall from January to December. The spatial trend of SPI12 drought classification is shown in Figure 3(d). In decade 1, mildly wet was observed in parts of Niger, Kaduna and the whole of Abuja while mild drought was observed at other parts of the study area. In decade 2, which is 
wetter than decade 1, mildly wet condition was observed across the study area except for parts of Jigawa, Yobe and Borno States. Decade 3 is wetter previous decades with mildly wet condition across the study area. Mild drought condition was observed only in Niger and parts of Kebbi in decade 4 while mildly wet was observed in other parts of the region. In decade 5, moderately wet was observed in parts of Taraba and Niger State while mildly wet was observed in remaining parts of Northern Nigeria in decade 6. A shift from a relatively wetter period to dry was observed between decades 7 and 9; mild drought was observed across the study area except for parts of Abuja, Kaduna, Plateau and Taraba in decade 7. Mild drought occurred across the study area in decade 8 and 9 (except for parts of Nguru).

Over Yelwa, negative anomaly was observed in Decades 5, 7 and 10 irrespective of SPI time-scale as shown in Figure 4 (a) above. Sokoto which is in upper-north, witnessed negative anomaly indicating drought was observed in decades 1,7 to 10, this shows persistent dryness between decade 7 and decade 10 except for SPI3 (decade 9) which shows positive anomaly. Kaduna shows persistent dryness between decade 6 to decade 9 except that SPI1 (decade 9) indicates positive anomaly. Over Katsina, cases of drought are also dated back to decade 7 and it was also sustained till decade 10 except for SPI3 (decade 9) and SPI1 (decade 10) which indicate positive anomaly.

Abuja observed negative anomaly irrespective of the SPI time-scales only in decade 5 as shown in Figure 4(b). Minna experienced drought irrespective of SPI time-scales in decades 4, 6 and 10 whereas Gombe observed negative anomalies in decades 1, 8, and 9 irrespective of the SPI time-scales Decade 7 also witnessed negative SPI values. Over Maiduguri, decades, 1, 3, 7, 8, 9 experienced great deal of negatives anomalies in their SPI time-scales only that decades 3 and 9 showed positive trend in 12 month and 3 month SPI respectively.

Over Nasarawa, Only decades 7 and 8 show persistent drought irrespective of the SPI time-scales as seen in Figure 4(c). Kaduna shows persistent dryness between decade 6 to decade 9 except that SPI1 (decade 9) indicates positive anomaly. Kano experienced negative anomalies from decade 7 to decade 9 irrespective of the SPI time-scale which took another dimension in the 10th decade. Bauchi experienced negative anomaly in decades 1 , 7, 8, and 9 respectively only that decade 9 witnessed positive SPI3 values. Nguru witnessed mild drought in decade 1 and negative anomalies in decades 7, 8 and 9.

Over Jos, negatives anomalies were observed in decades 8, 9 and 10 which indicates there's a perpetual near normal drought in those study years as shown in Figure 4(d). Likewise in Ibi, negative anomalies were observed in decades 8, 9 and 10 only that this time, decade 9 showed a positive in the SPI1 time scale. Yola is not left out with near normal drought in all the years of study with fluctuating positive and negative trends. In Gusau, decades 5, 7 and 10 witnessed near normal drought irrespective of the time scales used in the study.

Duste witnessed negative anomalies from decades 7 to 9 irrespective of the SPI timescales which indicates there's a perpetual mild drought and took a positive trend in decade 10 as shown in Figure 4(e) Makurdi showed more of positive trends where Ilorin and lokoja showed some similarities in their trends

Mild drought (Near Normal dry) has the highest occurrence across all stations within the 100 years of study as shown in Table 2 [16]. The number of occurrence per classification reduces with increasing severity. A closer examination of the number of occurrence of severe drought in the zone shows that the extreme northern parts and northeastern parts (i.e. Maiduguri, Gombe and Yola) are more susceptible to extreme and severe drought. On the other hand, this is in good agreement with earlier researchers that these areas are more prone to drought and desertification [18]-[20]

\section{Summary and Conclusion}

Drought occurs in every part of the globe and adversely affects the lives of a large number of people, causing considerable damage to economies, the environment, and property. It also affects countries or regions differently, having a greater impact on countries or regions with poor economic conditions. On many occasions droughts were so severe that local citizens were forced to leave their natural habitats. Findings revealed that this zone is generally replete with severe and prolonged drought events and that the catastrophic droughts of 1968-1973 did not start simultaneously in the whole of the region.

Analyses further revealed that the decade 7-decade 9 witnessed the persistent drought in the major parts of the northern Nigeria. Near normal dry or mild drought was predominant in the 100 years of study. Mild drought has the highest number of occurrence in the northern Nigeria. A closer examination shows that north-eastern part of Nigeria is susceptible to moderate drought. 

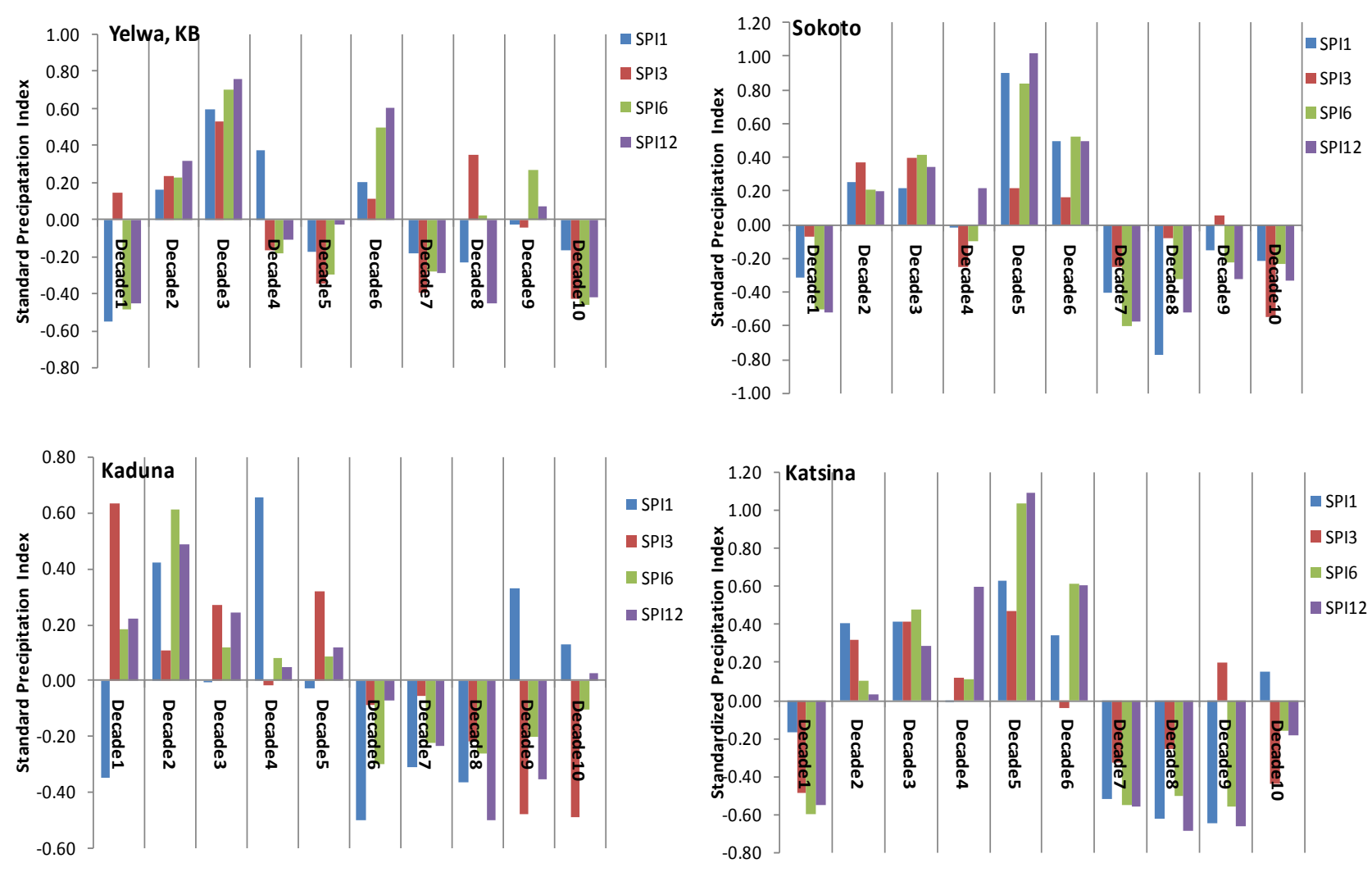

(a)
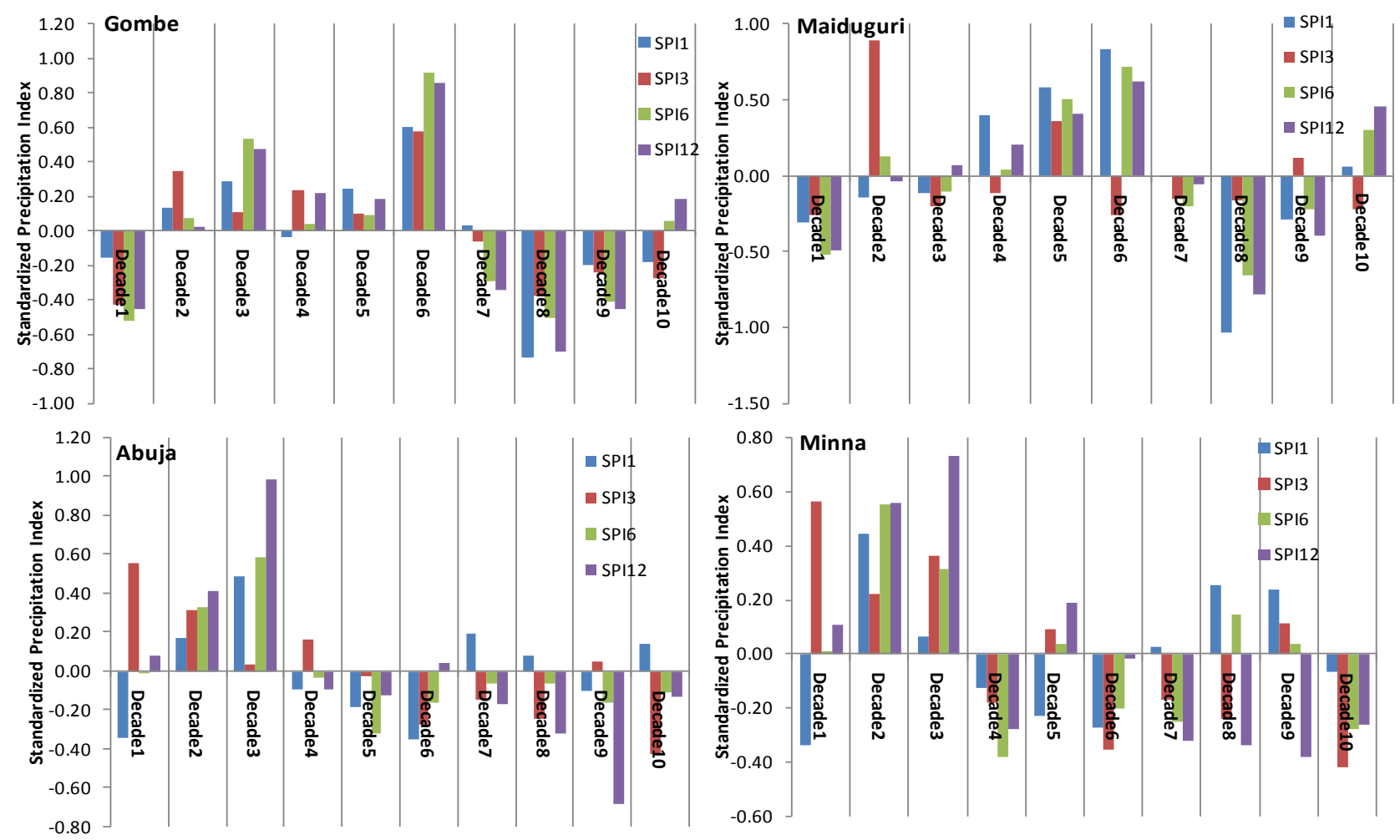

(b) 


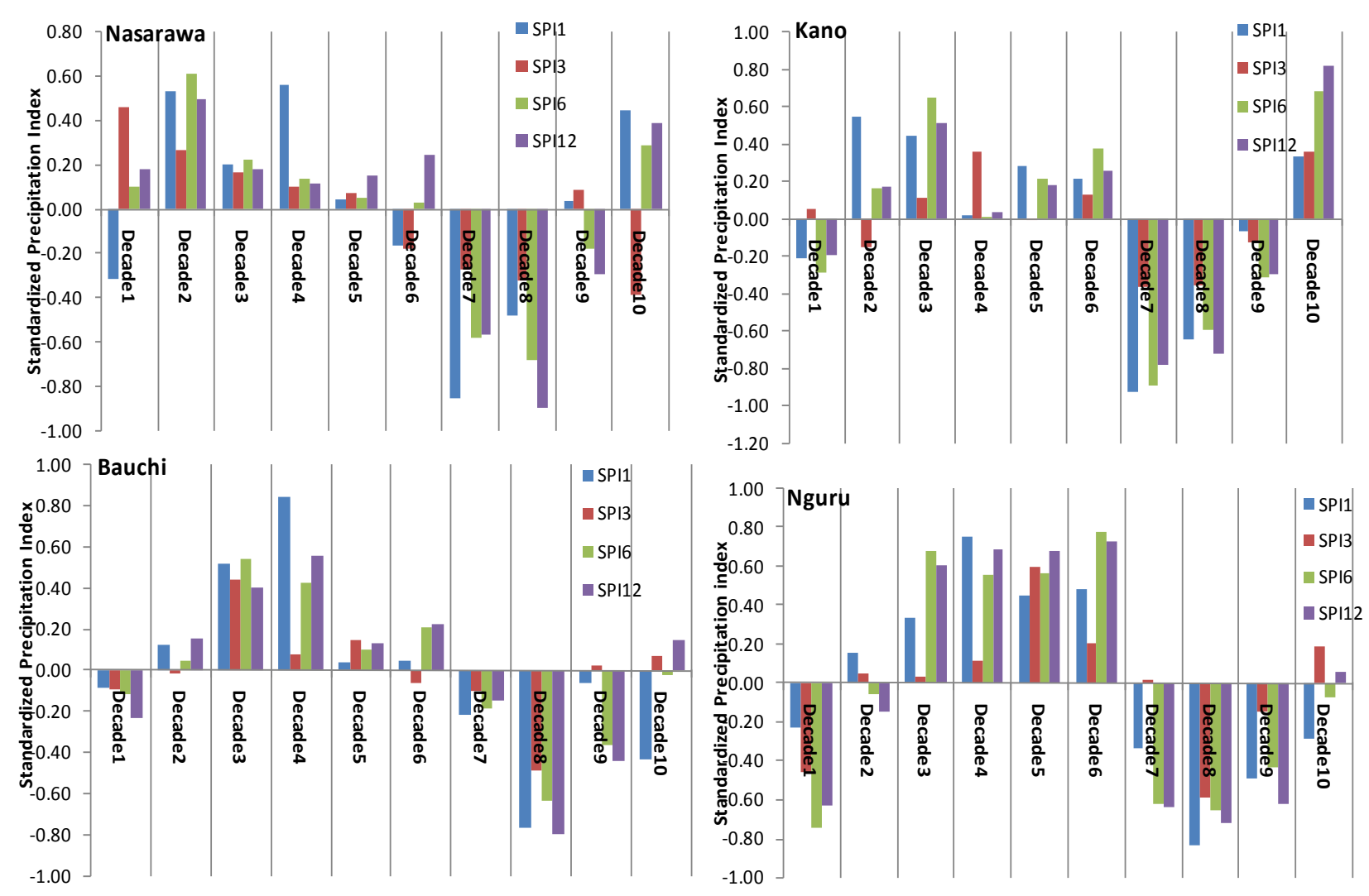

(c)
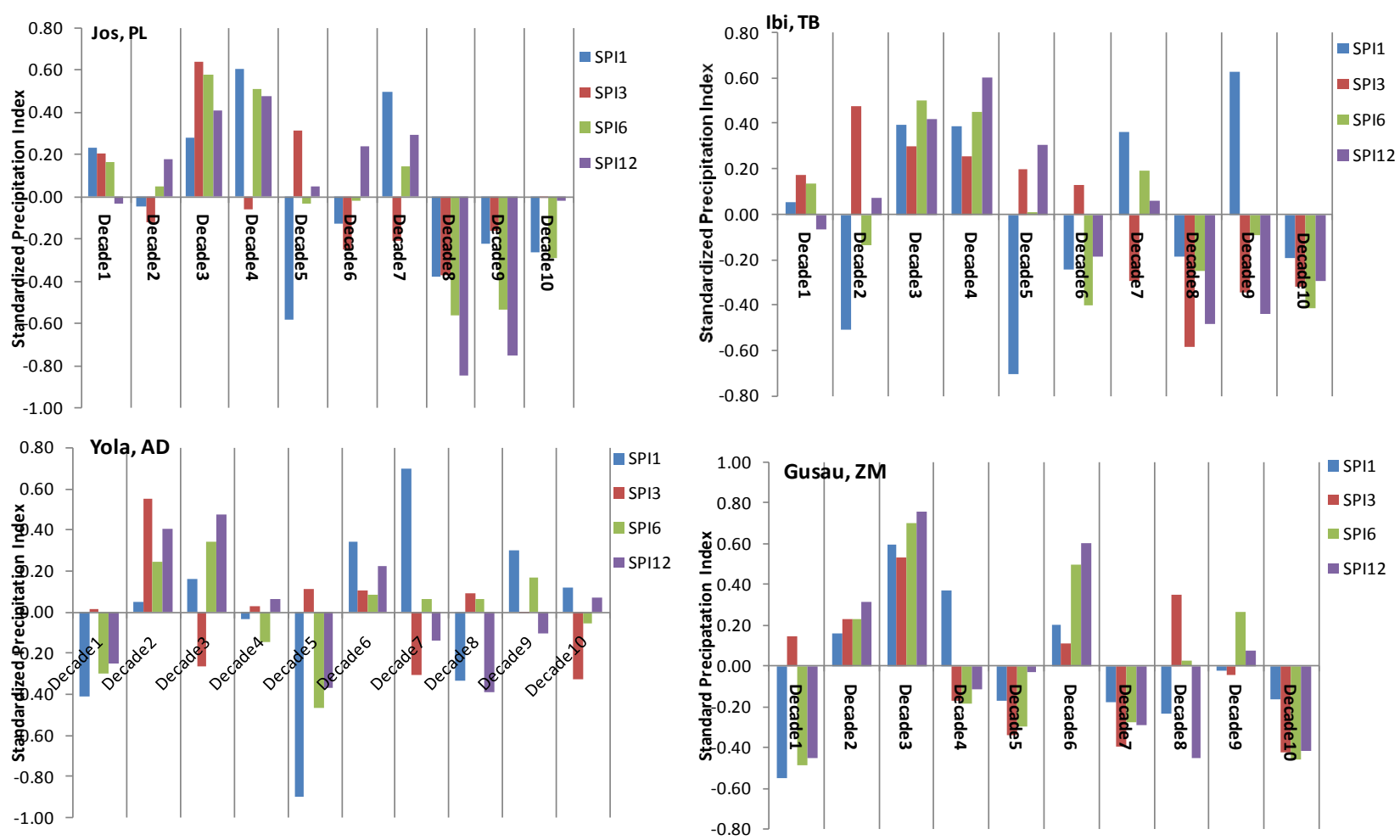

(d) 

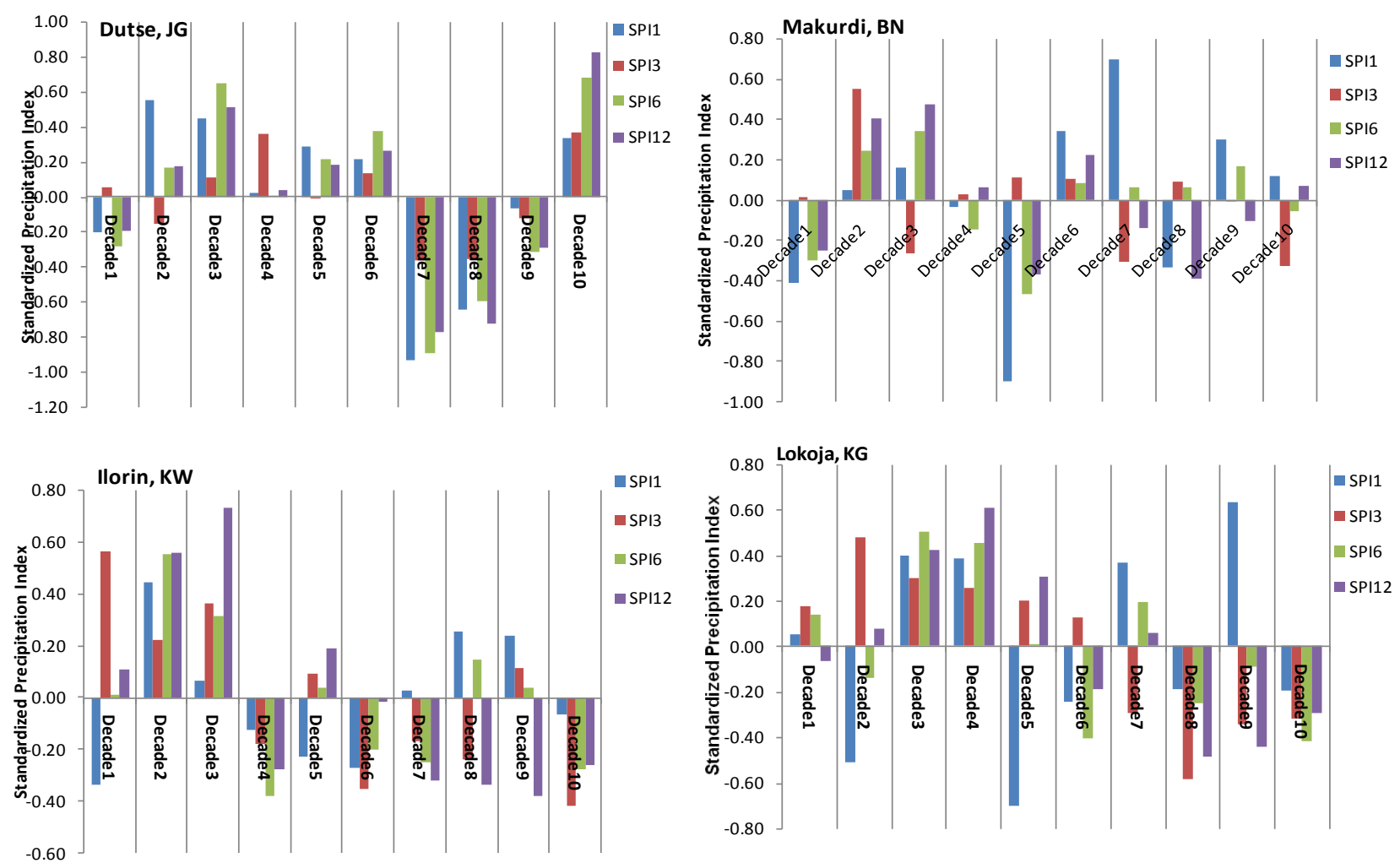

(e)

Figure 4. (a)-(e) for all locations show a distinct period of negative and positive values of Standadized precipitation Index, while nagative values indicate occurrence of drought and the positive implies no drought occurrence. (a) Decade 1-Decade 10 Standadized Precipitation Index (Yelwa, Sokoto, Kaduna, Katsina); (b) Decade 1-Decade 10 Standadized Precipitation Index (Gombe, Maiduguri, Abuja, Minna); (c) Decade 1-Decade 10 Standadized Precipitation Index (Nasarawa, Kano, Bauchi, Nguru); (d) Decade 1-Decade 10 Standadized Precipitation Index (Jos, Ibi, Yola, Gusau); (e) Decade 1-Decade 10 Standadized Precipitation Index (Dutse, Makurdi, Ilorin, Lokoja).

Table 2. Frequency of occurrence of drought from 1907-2006 ( Maiduguri, Gombe, Yola).

\begin{tabular}{|c|c|c|c|c|c|c|}
\hline \multirow{2}{*}{ MAIDUGURI } & \multirow{2}{*}{ SPI } & \multirow{2}{*}{ Classification } & \multicolumn{4}{|c|}{ Number of Occurrence in 100 Years } \\
\hline & & & SPI1 & SPI3 & SPI6 & SPI12 \\
\hline & $2.00>$ & Extremely wet & 2 & 4 & 2 & 0 \\
\hline & 1.50 to 1.99 & Very wet & 5 & 6 & 4 & 5 \\
\hline & 1.00 to 1.49 & Moderately wet & 8 & 3 & 11 & 11 \\
\hline & 0 to 0.99 & Near Normal wet & 29 & 27 & 32 & 38 \\
\hline & 0 to -0.99 & Near Normal dry & 40 & 44 & 36 & 32 \\
\hline & $(-1)$ to $(-1.49)$ & Moderately dry & 9 & 15 & 5 & 5 \\
\hline & $(-1.50)$ to $(-1.99)$ & Severely dry & 6 & 0 & 8 & 5 \\
\hline & $<-2.00$ & Extremely dry & 1 & 1 & 2 & 4 \\
\hline \multirow{3}{*}{ GOMBE } & \multirow{2}{*}{ SPI } & \multirow{2}{*}{ Classification } & \multicolumn{4}{|c|}{ Number of Occurrence in 100 Years } \\
\hline & & & SPI1 & SPI3 & SPI6 & SPI12 \\
\hline & $2.00>$ & Extremely wet & 4 & 3 & 2 & 1 \\
\hline
\end{tabular}




\begin{tabular}{|c|c|c|c|c|c|c|}
\hline \multicolumn{7}{|l|}{ Continued } \\
\hline & 1.50 to 1.99 & Very wet & 4 & 3 & 4 & 7 \\
\hline & 1.00 to 1.49 & Moderately wet & 6 & 7 & 12 & 9 \\
\hline & 0 to 0.99 & Near Normal wet & 32 & 34 & 32 & 31 \\
\hline & 0 to -0.99 & Near Normal dry & 41 & 37 & 34 & 39 \\
\hline & $(-1)$ to $(-1.49)$ & Moderately dry & 11 & 15 & 9 & 4 \\
\hline & $(-1.50)$ to $(-1.99)$ & Severely dry & 0 & 1 & 5 & 5 \\
\hline & $<-2.00$ & Extremely dry & 2 & 0 & 2 & 4 \\
\hline \multirow{2}{*}{ YOLA } & \multirow{2}{*}{ SPI } & \multirow{2}{*}{ Classification } & \multicolumn{4}{|c|}{ Number of Occurrence in 100 Years } \\
\hline & & & SPI1 & SPI3 & SPI6 & SPI12 \\
\hline & $2.00>$ & Extremely wet & 4 & 2 & 3 & 2 \\
\hline & 1.50 to 1.99 & Very wet & 4 & 2 & 2 & 5 \\
\hline & 1.00 to 1.49 & Moderately wet & 5 & 12 & 14 & 11 \\
\hline & 0 to 0.99 & Near Normal wet & 35 & 30 & 28 & 31 \\
\hline & 0 to -0.99 & Near Normal dry & 37 & 40 & 38 & 32 \\
\hline & $(-1)$ to $(-1.49)$ & Moderately dry & 9 & 8 & 6 & 12 \\
\hline & $(-1.50)$ to $(-1.99)$ & Severely dry & 5 & 6 & 7 & 6 \\
\hline & $<-2.00$ & Extremely dry & 1 & 0 & 2 & 1 \\
\hline
\end{tabular}

This study therefore confirmed that there is no coherent time pattern to the occurrence of drought. It also confirmed the high intensity of droughts in the decade 8 . The analysis showed some stations to be on what can be termed recovery (Kano, for example) to wet situations in the last two decades. This study proves the need to put measures in place that are likely to be used to tackle and ameliorate the impact of drought when they next re-occur.

\section{Acknowledgements}

The authors acknowledge the Climate and Research Unit (CRU) and Nigerian Meteorological Agency (NIMET) for providing data input and coordinates for this work.

\section{References}

[1] Adefolalu, D.O. (1983) Desertification in the Sahel. In: OoiJin-Bee, Ed., Natural Resource in Tropical Countries, Singapore University Press, Singapore City, 402-438.

[2] Oguntoyinbo, J.S. and Richards, P. (1977) The Extent and Intensity of 1969-1973 Drought in Nigeria.

[3] Adefolalu, D.O. (1986) Further Aspects of Sahelian Drought as Evident from Rainfall Regime of Nigeria. Archives for Meteorology, Geophysics and Bioclimatology, Series B, 36, 277-295.

[4] Adefolalu, D.O. (1990) Desertification Studies. In: Vaughan, Ed., Microwave Remote Sensing, Kluwer Pub., Dordrecht, Boston and London, 278-305.

[5] Ojo, O. (1987) Rainfall Trends in West Africa, 1901-1985. In: Solomon, S.I., Beran, M. and Hogg, W., Eds., The Influence of Climate Change and Climate Variability on the Hydrologic Regime and Water Resources (Proceedings of the Vancouver Symposium, August 1987), No. 168, IAHS Publication, Canada.

[6] Usman, M.T. (1993) An Operation Index for Assessing Inter Annual Rainfall Variability and Agricultural Drought over Sahel. Africa Climate Research Services.

[7] Nimet (2001) Nimet Bulletin on Drought Monitor. www.nimetng.org/nimet

[8] Charney, Jule, Quirk, W.J., Chow, S.-H. and Kornfield, J. (1977) A Comparative Study of the Effect of Albedo Change in Drought in Semi-Arid Regions. Journal of the Atmospheric Sciences, 34, 1360-1384. 
[9] Lamb, H.H. (1979) Climate, Past, Present and Future. Mettuen, London, 831.

[10] Lamb, J.P. (1978) Change of Sahel Rainfall as a Function of the Position of ITCZ.

[11] Nicholson, S.E. (1989) Long-Term Changes in African Rainfall. Weather, 44, 46-56. http://dx.doi.org/10.1002/j.1477-8696.1989.tb06977.x

[12] Nicholson, S.E., Some, B. and Kone, B. (2000) An Analysis of Recent Rainfall Conditions in West Africa, Including the Rainy Seasons of the 1997.

[13] Ekpoh, I.J. (2007) Climate and Society in Northern Nigeria: Rainfall Variability and Faming. The International Journal Series on Tropical Issues, 8, 157-162.

[14] Kamara, S.I. (1986) The Origin and Types of Rainfall in West Africa. Weather, 41, 48-56.

[15] Kalu, A.E. (1987) The Recurrence of Severe Droughts in Northern Nigeria. Proceedings of the 1985 Commonwealth Meteorologists Conference, Meteorological Office College, Reading.

[16] McKee, T.B., Doesken, N.J. and Kleist, J. (1993) The Relationship of Drought Frequency and Duration to Time Scales. Preprints, 8th Conference on Applied Climatology, Anaheim, 17-22 January 1993, 179-184.

[17] Simple Linear Regression. http://www.oxfordjournals.org/our_journals/tropej/online/ma_chap2.pdf

[18] Ayuba, H.K., Maryah, U.M. and Gwary, D.M. (2007) Climate Change Impact on Plant Species Composition in Six Semi-Arid Rangelands of Northeastern Nigeria. The Nigerian Geographical Journal, 5, 35-42.

[19] Federal Republic of Nigeria, FRN (2000) National Action Program (NAP) to Combat Desertification and Mitigate the Effect of Drought. Towards the Implementation of the United Nations Convention to Combat Desertification and Mitigate the Effect of Drought in the Country.

[20] Oladipo, E.O. (1993) Some Aspects of the Spatial Characteristics of Drought in Northern Nigeria. Natural Hazards, 8, 171-188. 
Scientific Research Publishing (SCIRP) is one of the largest Open Access journal publishers. It is currently publishing more than 200 open access, online, peer-reviewed journals covering a wide range of academic disciplines. SCIRP serves the worldwide academic communities and contributes to the progress and application of science with its publication.

Other selected journals from SCIRP are listed as below. Submit your manuscript to us via either submit@scirp.org or Online Submission Portal.
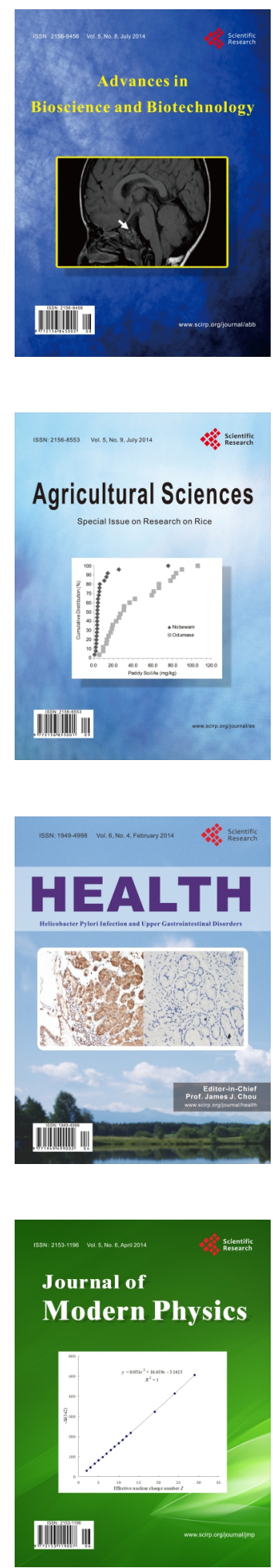
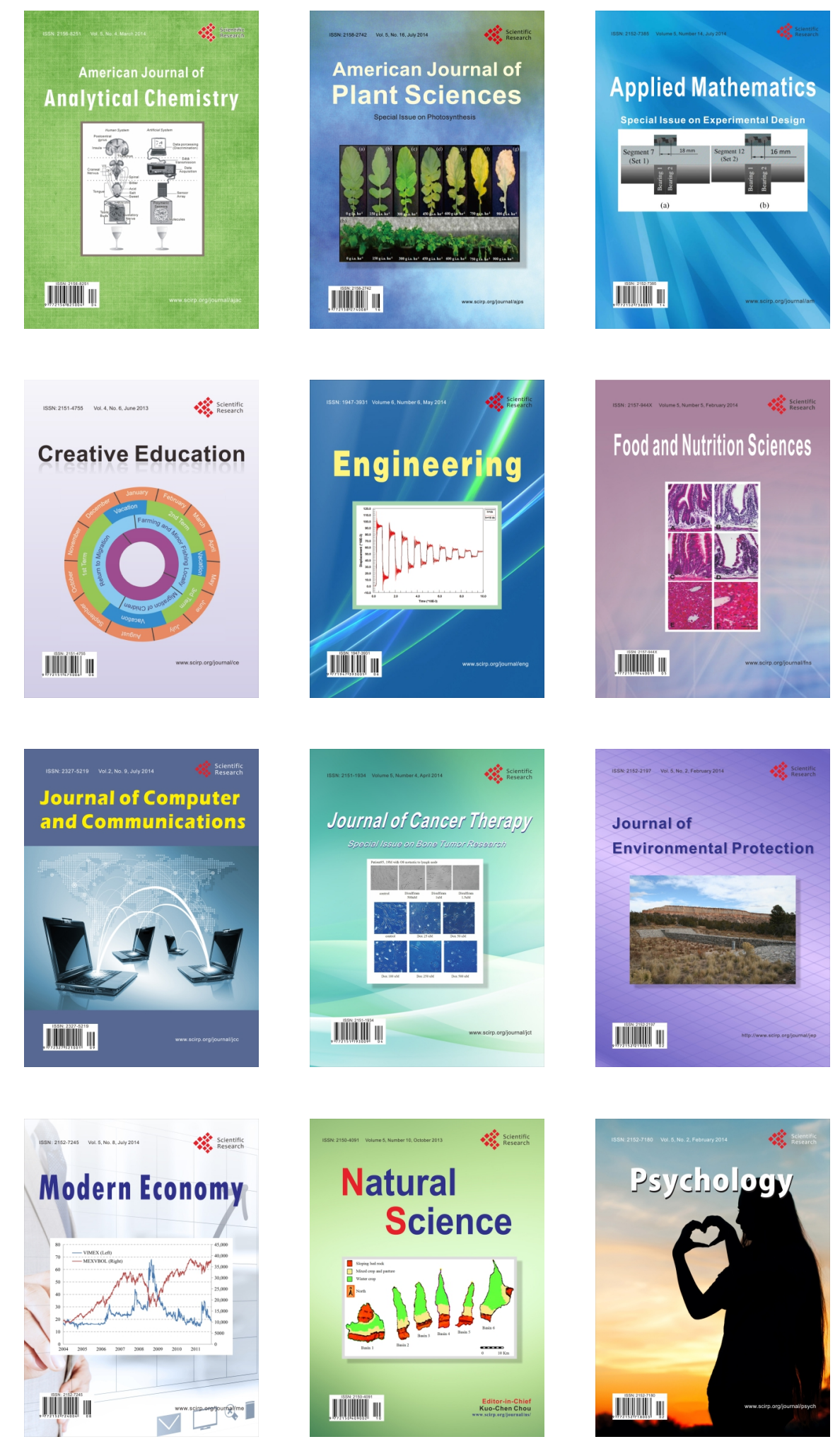